\title{
Keller-Box Analysis of Buongiorno Model with Brownian and Thermophoretic Diffusion for Casson Nanofluid over an Inclined Surface
}

\author{
Khuram Rafique ${ }^{1}$, Muhammad Imran Anwar ${ }^{1,2,3}$, Masnita Misiran ${ }^{1}$, Ilyas Khan ${ }^{4, *} \mathbb{C}$, \\ Sayer O. Alharbi ${ }^{5}$, Phatiphat Thounthong ${ }^{6}$ and Kottakkaran Sooppy Nisar ${ }^{7}$ \\ 1 School of Quantitative Sciences, Universiti Utara Malaysia, Sintok 06010, Kedah, Malaysia; \\ Khurram.rafique1005@gmail.com (K.R.); masnita@uum.edu.my (M.M.) \\ 2 Department of Mathematics, Faculty of Science, University of Sargodha, Sargodha 40411, Pakistan \\ 3 Higher Education Department (HED), Punjab 54000, Pakistan; imrananwar@uos.edu.pk \\ 4 Faculty of Mathematics and Statistics, Ton Duc Thang University, Ho Chi Minh City 72915, Vietnam \\ 5 Department of Mathematics, College of Science Al-Zulfi, Majmaah University, Al-Majmaah 11952, \\ Saudi Arabia; so.alharbi@mu.edu.sa \\ 6 Renewable Energy Research Centre, Department of Teacher Training in Electrical Engineering Faculty of \\ Technical Education King Mongkut's University of Technology North Bangkok, 1518, Pracharat 1 Rd., \\ Bangsue, Bangkok 10800, Thailand; phatiphat.t@fte.kmutnb.ac.th \\ 7 Department of Mathematics, College of Arts and Science, Prince Sattam bin Abdulaziz University, \\ Wadi Al-Dawaser 11991, Saudi Arabia; n.sooppy@psau.edu.sa \\ * Correspondence: ilyaskhan@tdtu.edu.vn
}

Received: 10 August 2019; Accepted: 17 September 2019; Published: 5 November 2019

\begin{abstract}
The key objective of the study under concern is to probe the impacts of Brownian motion and thermophoresis diffusion on Casson nanofluid boundary layer flow over a nonlinear inclined stretching sheet, with the effect of convective boundaries and thermal radiations. Nonlinear ordinary differential equations are obtained from governing nonlinear partial differential equations by using compatible similarity transformations. The quantities associated with engineering aspects, such as skin friction, Sherwood number, and heat exchange along with various impacts of material factors on the momentum, temperature, and concentration, are elucidated and clarified with diagrams. The numerical solution of the present study is obtained via the Keller-box technique and in limiting sense are reduced to the published results for accuracy purpose.
\end{abstract}

Keywords: Keller-box technique; Casson nanofluid; MHD; Power law fluid; Convective boundaries; Radiation effect; Inclined surface

\section{Introduction}

Brownian motion and thermophoresis diffusions are the key notions of abnormal improvement in thermal conductivity by using binary fluids (base fluid along with nanoparticles). The influence of Brownian motion and thermophoresis is focused in the Buongiorno model. This model supports engineers and scholars through its utilization in the field of science and technology. It is also pointed out that nanoparticles occupying Brownian motion and thermophoresis effects cause improvement of thermal conductivity. The Brownian motion principle along thermophoresis particle installation supports, in manufacturing, germanium dioxide optical fibers and, in communication engineering, silicon. The impacts of Brownian motion and thermophoresis diffusion on Casson nanofluid flow on a stretching sheet were discussed by Anwar et al. [1]. Afify [2] scrutinized the Brownian movement and thermophosis impact on Casson nanofluid flow with convective boundaries. The impacts of radiations 
on Casson nanofluid flow with Brownian motion and thermophoresis influence were studied by Souayeh et al. [3]. Rashidi et al. [4] discussed heat exchange and particle motion by considering the discrete phase model (DPM). Bhatti et al. [5] examined electro-magnetohydrodynmaic (MHD) flow with heat exchange by incorporating the thermal radiations effect. Ellahi et al. [6] investigated a shiny thin film with metallic tactile covering nanoparticles through a rotating disk. Numerous scholars [7-12] considered the Buongiorno model to investigate flow characteristics.

The most significant concerns of a creator and craftsman in the construction of different items, in the pursuit of excellence, is the lessening of expenses and time. The role of heat and fluids in industries is undeniable. Discovering approaches towards the advancement of procedures and the quantity of energy exchange has consistently been a concern for researchers and specialists from the earlier times to the current era. The discovery of nanoparticles and the advancement in nanotechnology is viewed as a tremendous change in innovation and science. Choi [13] was the initiator of the nanofluid concept. A mixture of a base fluid (water, ethylene glycol and so on) with nano-scale particles called nanoparticles is termed as a nanofluid. Nanofluids have a higher thermal conductivity as compared to base fluids, due to which the energy exchange procedure is enhanced. The radiation effects on Casson nanofluid flow on a nonlinear slanted sheet were investigated by Ghadikolaei et al. [14]. The effect of a magnetic field on the flow of a nanofluid over an inclined sheet was studied by Suriyakumar and Devi [15]. Khan et al. [16] examined the flow of a Jeffery nanofluid over a slanted sheet. Thumma et al. [17] discussed the flow of a nanofluid over a nonlinear inclined stretching sheet. Parkash et al. [18] discussed the nanofluid flow through a channel analytically. Zeeshan et al. [19] examined the flow of titanium dioxide-water base nanofluid because of entropy generation. Shehzad et al. [20] calculated the silver-water base nanofluid flow in a porous medium because of entropy generation. Hussain et al. [21] studied multiphase flow synthesis with nano-size hafnium particles with the effect of electro-hydrodynamic effect. Ellahi et al. [22] discussed the thermally charged MHD bi-phase flow coating with non-Newtonian nanofluid along slipper walls. Recently, many scholars discussed nanofluid flow by incorporating different impacts [23-26].

Non-Newtonian fluids have gained considerable attention from scientists and engineers because of their key role in the field of industry and engineering. The study under concern has direct noteworthy use in association with non-Newtonian fluids, such as Casson fluids (honey, human blood etc.), power law fluids and nanofluids etc. Reddy [27] investigated the movement of Casson liquid over a slanted sheet. Hakeem et al. [28] investigated the inclined Lorentz force on Casson fluid flow on an extended sheet. Rawi et al. [29] studied the unsteady flow of Casson fluid through a slanted sheet. Casson fluid flow on an inclined sheet with multiple impacts was discussed by Jain and Parmar [30]. Ellahi et al. [31] discussed the two-phase Couette flow of couple stress by incorporating the magnetic field impacts. Ellahi et al. [32] investigated the blood flow of couple stress fluid with chemical reaction effects. For further detailed literature related to non-Newtonian fluid flow on inclined sheets, see [33-40].

Heat exchange due to thermal radiations has become an active area of research due to its vast range of applications in the field of nuclear power plants, missiles, satellites and in nanotechnology. Moreover, it is significant that thermal radiation is not suitable for the engineering of thermal tools with large variations in temperature [41]. The thermal radiation impact on flow and heat exchange is a key factor to design advanced energy conversion systems [42]. Recently, Ghadikolaei et al. [43] investigated the flow of Casson nanofluid on a porous inclined sheet numerically. Saidulu [44] discussed the radiation impacts on the flow of a nanofluid over an exponential inclined surface.

To the best of the authors' knowledge, no study on Casson nanofluid flow over an inclined nonlinear stretching sheet along with radiation effects and convective boundaries has been reported yet. Besides, the fact that a lot of work has already been done on non-Newtonian fluids with different geometries, but due to the growing applications of non-Newtonian fluids in the field of industry, the authors choose this study on an inclined sheet. The non-Newtonian fluid flow on an inclined sheet 
plays a vital role in MHD generators, gas turbines, and extrusion of plastic sheets. The numerical solution of the current problem is obtained using the Keller-box method.

\section{Problem Formulation}

Suppose two-dimensional incompressible Casson nanofluid flow over a nonlinear inclined stretching sheet slanted at $\gamma$, where $u_{w}(x)=a x^{m}$ is the extending speed and $u_{\infty}(x)=0$ is free stream speed, in which $x$ is the coordinate stated towards the extending sheet and ' $a$ ' is considered as constant. The transverse magnetic field ' $B_{0}$ ' is taken as normal to the track of flow. The Brownian motion and thermophoresis effects are considered. The temperature $T$ and nanoparticle fraction $C$ take the values $T_{w}$ and $C_{w}$ at the wall. The thermal radiation impact is incorporated with a convective heating procedure considered by the temperature $T_{f}$ and heat exchange factor $h_{f}$, which is proportional to $x^{-1}$. Meanwhile, the encompassing structures for nanofluid temperature and mass divisions $T_{\infty}$ and $C_{\infty}$ are achieved as y keeps an eye on infinity, as displayed in Figure 1.

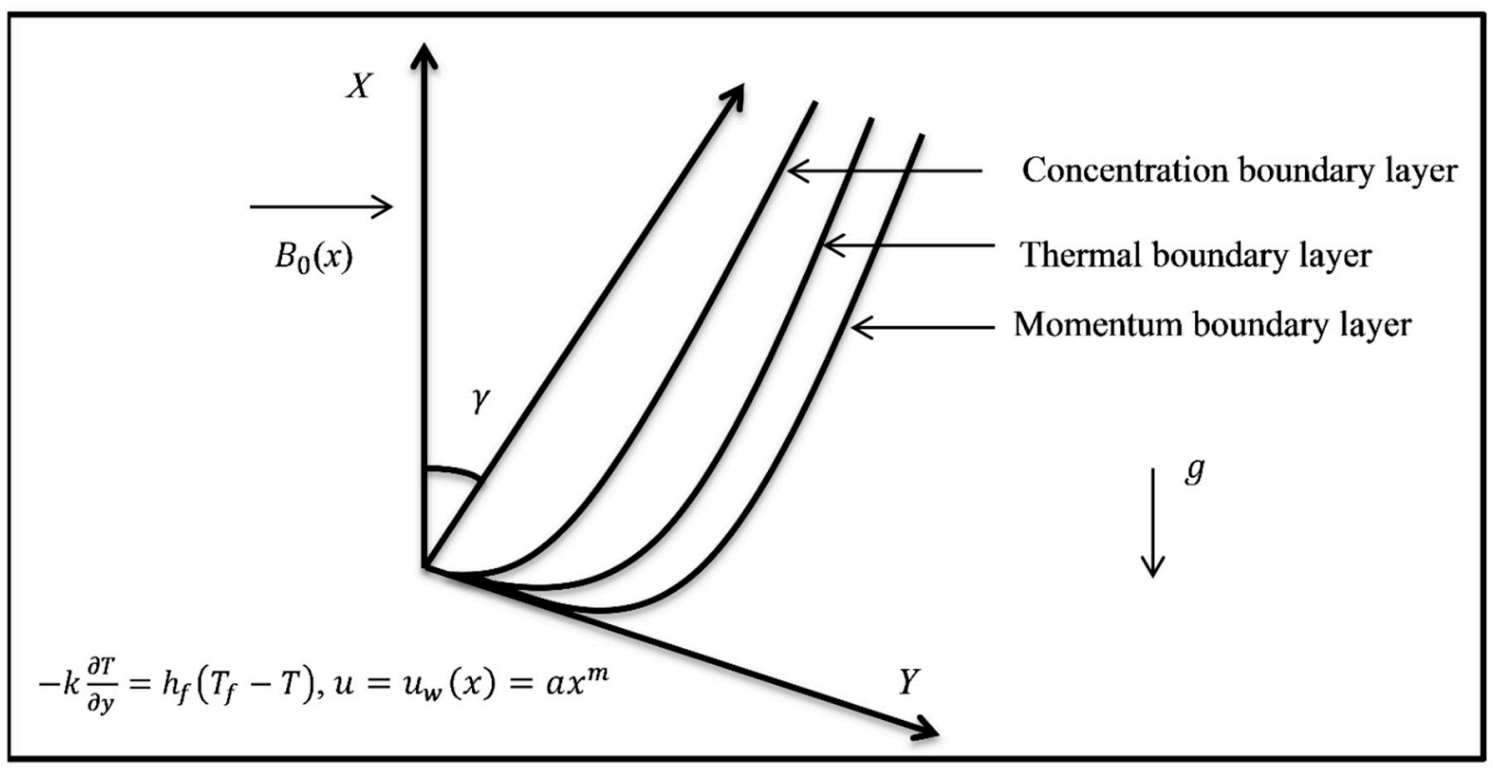

Figure 1. Physical geometry with coordinate system.

The flow equations for this study are given by

$$
\begin{gathered}
\frac{\partial u}{\partial x}+\frac{\partial v}{\partial y}=0 \\
u \frac{\partial u}{\partial x}+v \frac{\partial u}{\partial y}=v\left(1+\frac{1}{\beta}\right) \frac{\partial^{2} u}{\partial y^{2}}+g\left[\beta_{t}\left(T-T_{\infty}\right)+\beta_{c}\left(C-C_{\infty}\right)\right] \cos \gamma-\frac{\sigma B_{0}^{2}(x)}{\rho} u \\
u \frac{\partial T}{\partial x}+v \frac{\partial T}{\partial y}=\alpha \frac{\partial^{2} T}{\partial y^{2}}-\frac{1}{(\rho c)_{f}} \frac{\partial q_{r}}{\partial y}+\tau\left[D_{B} \frac{\partial C}{\partial y} \frac{\partial T}{\partial y}+\frac{D_{T}}{T_{\infty}}\left(\frac{\partial T}{\partial y}\right)^{2}\right] \\
u \frac{\partial C}{\partial x}+v \frac{\partial C}{\partial y}=D_{B} \frac{\partial^{2} C}{\partial y^{2}}+\frac{D_{T}}{T_{\infty}} \frac{\partial^{2} T}{\partial y^{2}} .
\end{gathered}
$$

Here, the Rosseland estimation (for radiation flux) is characterized as

$$
q_{r}=-\frac{4 \sigma^{*}}{3 k^{*}} \frac{\partial T^{4}}{\partial y}
$$


where the Stephen-Boltzmann coefficient is given by $\sigma^{*}$ and the mean absorption constant is represented by $k^{*}$. Meanwhile, the temperature changes between the local temperature $T$ and free steam $T_{\infty}$ are very small, by ignoring higher order terms in the expansion of $T^{4}$ in Taylor succession about $T_{\infty}$ for:

$$
T^{4} \cong 4 T_{\infty}^{3} T-3 T_{\infty}^{4}
$$

By using Equations (5) and (6), the Equation (3) is converted into

$$
u \frac{\partial T}{\partial x}+v \frac{\partial T}{\partial y}=\left(\alpha+\frac{16 \sigma^{*} T_{\infty}^{3}}{3 k^{*}(\delta c)_{f}}\right) \frac{\partial^{2} T}{\partial y^{2}}+\tau\left[D_{B} \frac{\partial C}{\partial y} \frac{\partial T}{\partial y}+\frac{D_{T}}{T_{\infty}}\left(\frac{\partial T}{\partial y}\right)^{2}\right],
$$

where in the directions $x$ and $y$, the velocity constituents are $u$ and $v$, individually, $g$ is the gravitational acceleration, the strength of the magnetic field is defined by $B_{0}, \sigma$ is the electrical conductivity, viscosity is given by $\mu$, the density of conventional fluid is given by $\rho_{f}$, the density of the nanoparticle is given by $\rho_{p}, \beta$ is the Casson parameter, the thermal expansion factor is denoted by $\beta_{t}$, the concentration expansion constant is given by $\beta_{c}, D_{B}$ denotes the Brownian dissemination factor and $D_{T}$ represents the thermophoresis dispersion factor. The thermal conductivity is given by $k$, the heat capacity of the nanoparticles symbolically is given as $(\rho c)_{p}$, the heat capacity of the conventional liquid is given by $(\rho c)_{f}, \alpha=\frac{k}{(\rho c)_{f}}$ denotes the thermal diffusivity parameter, and the symbolic representation of the relation among the current heat capacity of the nanoparticle and the liquid is $\tau=\frac{(\rho c)_{p}}{(\rho c)_{f}}$.

In this problem, boundary conditions are considered as

$$
\begin{gathered}
u=u_{w}(x)=a x^{m}, v=0,-k \frac{\partial T}{\partial y}=h_{f}\left(T_{f}-T\right), C=C_{w} \text { at } y=0, \\
u \rightarrow u_{\infty}(x)=0, v \rightarrow 0, T \rightarrow T_{\infty}, C \rightarrow C_{\infty} \text { at } y \rightarrow \infty
\end{gathered}
$$

For the conversion of the Equations (2), (4) and (7) into ordinary differential equations, we use $\psi=\psi(x, y)$, called the stream function, characterized as

$$
u=\frac{\partial \psi}{\partial y}, \quad v=-\frac{\partial \psi}{\partial x} .
$$

The similarity transformations are considered as

$$
\psi=\sqrt{\frac{2 v a x^{m+1}}{m+1}} f(\eta), \theta(\eta)=\frac{T-T_{\infty}}{T_{w}-T_{\infty}}, \phi(\eta)=\frac{C-C_{\infty}}{C_{w}-C_{\infty}}, \eta=y \sqrt{\frac{(m+1) a x^{m-1}}{2 v}}
$$

By using Equations (9) and (10), Equation (1) is fulfilled indistinguishably. Besides, Equations (2), (4) and (7) are transformed to the following

$$
\begin{aligned}
& \left(1+\frac{1}{\beta}\right) f^{\prime \prime \prime}+f f^{\prime \prime}-\left(\frac{2 m}{m+1}\right) f^{\prime 2}+\frac{2}{m+1}(\lambda \theta+\delta \phi) \cos \gamma-\left(\frac{2 M}{m+1}\right) f^{\prime}=0 \\
& \operatorname{Pr}_{N} \theta^{\prime \prime}+f \theta^{\prime}+N b \phi^{\prime} \theta^{\prime}+N t \theta^{\prime 2}=0 \\
& \phi^{\prime \prime}+\operatorname{Lef} \phi^{\prime}+N t_{b} \theta^{\prime \prime}=0
\end{aligned}
$$

where

$$
\begin{gathered}
\lambda=\frac{G r_{x}}{R e_{x}^{2}}, \delta=\frac{G c_{x}}{R e_{x}^{2}}, M=\frac{\sigma B_{0}^{2}(x)}{a \rho}, L e=\frac{v}{D_{B}} \operatorname{Pr}=\frac{v}{\alpha}, N_{b}=\frac{\tau D_{B}\left(C_{w}-C_{\infty}\right)}{v}, \\
N_{t}=\frac{\tau D_{t}\left(T_{w^{\prime}}-T_{\infty}\right)}{v T_{\infty}}, N t_{b}=\frac{N_{t}}{N_{b}}, G r_{x}=\frac{g \beta_{t}\left(T_{w}-T_{\infty}\right) x^{3}}{v^{2}}, R e_{x}=\frac{u_{v w} x}{v}, G c_{x}=\frac{g \beta_{c}\left(C_{w}-C_{\infty}\right) x^{3}}{v^{2}}, \\
\operatorname{Pr}_{N}=\frac{1}{P r}\left(1+\frac{4}{3} N\right), N=\frac{4 \sigma^{*} T_{\infty}^{3}}{\alpha k^{*}} .
\end{gathered}
$$


Here, primes signify the differentiation concerning $\eta, \lambda$ is the buoyancy parameter, $\delta$ is the solutal buoyancy parameter, the magnetic constraint is given by $M, v$ denotes the kinematic viscosity of the liquid, the Prandtl number is given as $P r$, the Lewis number is given by $L e, N_{b}$ denotes the Brownian motion parameter, $N_{t}$ indicates the thermophoresis factor and $N$ denotes the radiation factor.

The resultant boundary settings are

$$
\begin{aligned}
f(\eta)=0, f^{\prime}(\eta) & =1, \theta^{\prime}(0)=-\gamma_{1}(1-\theta(0)), \phi(\eta)=1 \text { at } \eta=0, \\
f^{\prime}(\eta) & \rightarrow 0, \theta(\eta) \rightarrow 0, \phi(\eta) \rightarrow 0 \text { as } \eta \rightarrow \infty .
\end{aligned}
$$

Here, $\gamma_{1}=\frac{n}{k \sqrt{R e_{x}}}$ is the convective parameter termed as Biot number.

The skin friction, Sherwood number and Nusselt number for the current study are regarded as

$$
N u_{x}=\frac{x q_{w}}{k\left(T_{w}-T_{\infty}\right)}, S h_{x}=\frac{x q_{m}}{D_{B}\left(C_{w}-C_{\infty}\right)}, C_{f}=\frac{t_{w}}{u_{w}^{2} \rho_{f}}
$$

where

$$
q_{w}=-\left[k+\frac{4 \sigma^{*} T_{\infty}^{3}}{3 k^{*}},\right] \frac{\partial T}{\partial y}, q_{m}=-D_{B} \frac{\partial C}{\partial y}, \tau_{w}=\mu\left(1+\frac{1}{\beta}\right) \frac{\partial u}{\partial y}, \text { at } y=0 .
$$

The related terms of dimensionless reduced Nusselt number $-\theta^{\prime}(0)$, reduced Sherwood number $-\phi^{\prime}(0)$ and skin friction coefficient $C_{f x}=\left(1+\frac{1}{\beta}\right) f^{\prime \prime}(0)$ are defined as

$$
-\theta^{\prime}(0)=\frac{N u_{x}}{\left(1+\frac{4}{3} N\right) \sqrt{\frac{m+1}{2} R e_{x}}},-\phi^{\prime}(0)=\frac{S h_{x}}{\sqrt{\frac{m+1}{2} R e_{x}}}, C_{f x}=C_{f} \sqrt{\frac{2}{m+1} R e_{x}}
$$

where $R e_{x}=\frac{u_{w} x}{v}$, is the local Reynolds number.

The converted nonlinear differential Equations (11)-(13) with the boundary settings (15) are elucidated by a Keller-box scheme consisting of the steps as finite-differences scheme, Newton's technique and block elimination process, clearly explained by Anwar et al. [7]. The Keller-box technique has been widely applied because it is the most flexible as compared to other approaches. It is informal to practice, much quicker, friendly to program and effective.

\section{Results and Discussion}

In this part of the study, the numerical outcomes of the converted nonlinear ordinary differential Equations (11)-(13) with boundary settings (15) are elucidated by the Keller-box method. For the numerical results of physical parameters of our concern, namely, Brownian motion denoted by $\mathrm{Nb}$, thermophoresis given by $N t$, magnetic factor $M$, buoyancy factor $\lambda$, solutal buoyancy constraint $\delta$, inclination factor $\gamma$, Prandtl number $P r$, Lewis number $L e$, radiation factor $N$, Casson fluid parameter $\beta$, Biot number $\gamma_{1}$ and parameter $m$, several figures and tables are prepared. In Table 1 , in the deficiency of $\lambda, \delta, M$, and $N$, and taking factor $m=1$, with $\gamma=90^{\circ}$ and $\beta \rightarrow \infty$, the outcomes of $-\theta^{\prime}(0),-\phi^{\prime}(0)$ (reduced Nusselt number, reduced Sherwood number) are equated with the results of Khan and Pop [45]. The magnitudes are established as brilliant settlement. The effects on $-\theta^{\prime}(0),-\phi^{\prime}(0)$ and $C_{f x}(0)$ against several values of involved physical parameters $N b, \beta, N t, M, N, \lambda, \delta, \gamma, \operatorname{Pr}, L e, \gamma_{1}$ and $m$ are presented in Table 2. It is noted that $-\theta^{\prime}(0)$ drops when increasing the values of $N b, P r, \beta, N$, $L e, m$, and $\gamma_{1}$, and it increased by enhancing the numerical values of $\gamma, \lambda, \delta, M$ and $N t$. Moreover, it is perceived that $-\phi^{\prime}(0)$ is enhanced with larger values of $N b, P r, N, L e, \lambda$, and $\delta$, and drops for bigger values of $m, M, \beta, \gamma, \gamma_{1}$ and Nt. Physically, by enhancing the Brownian motion impact, the thermal boundary layer thickness increases, and it effects a large amount of the fluid. Moreover, the Sherwood number increases and the Nusselt number decreases as we boost the thermophoresis effect; this is due to the fact that the thermal boundary layer turns thicker due to deeper diffusion penetration into 
the fluid. On the other hand, $C_{f x}(0)$ rises with the growing values of $N b, P r, L e, \beta, M, N, \gamma$, and $m$, and drops with the higher values of $N t, \lambda, \delta, \gamma_{1}$ and $P r$.

Table 1. Contrast of the reduced Nusselt number $-\theta^{\prime}(0)$ and the reduced Sherwood number $-\phi^{\prime}(0)$ against $\gamma=90^{\circ}, \gamma_{1} \rightarrow \infty, \beta \rightarrow \infty, M, N, \lambda, \delta=0$, with $m=1$, and $\operatorname{Pr}=L e=10$.

\begin{tabular}{|c|c|c|c|c|c|}
\hline \multirow{2}{*}{$N b$} & \multirow{2}{*}{$N t$} & \multicolumn{2}{|c|}{ Khan and Pop [45] } & \multicolumn{2}{|c|}{ Present Results } \\
\hline & & $-\theta^{\prime}(0)$ & $-\phi^{\prime}(0)$ & $-\theta^{\prime}(0)$ & $-\phi^{\prime}(0)$ \\
\hline 0.1 & 0.1 & 0.9524 & 2.1294 & 0.9524 & 2.1294 \\
\hline 0.2 & 0.2 & 0.3654 & 2.5152 & 0.3654 & 2.5152 \\
\hline 0.3 & 0.3 & 0.1355 & 2.6088 & 0.1355 & 2.6088 \\
\hline 0.4 & 0.4 & 0.0495 & 2.6038 & 0.0495 & 2.6038 \\
\hline 0.5 & 0.5 & 0.0179 & 2.5731 & 0.0179 & 2.5731 \\
\hline
\end{tabular}

Table 2. Values of the reduced Nusselt number $-\theta^{\prime}(0)$, the reduced Sherwood number $-\phi^{\prime}(0)$ and the skin friction coefficient $C_{f x}(0)$.

\begin{tabular}{ccccccccccccccc}
\hline $\mathbf{N b}$ & $\boldsymbol{N} \boldsymbol{t}$ & $\mathbf{P r}$ & $\boldsymbol{L} \boldsymbol{e}$ & $\boldsymbol{M}$ & $\boldsymbol{N}$ & $\boldsymbol{\beta}$ & $\boldsymbol{\lambda}$ & $\boldsymbol{\delta}$ & $\boldsymbol{\gamma}_{1}$ & $\boldsymbol{m}$ & $\boldsymbol{\gamma}$ & $-\boldsymbol{\theta}^{\prime}(\mathbf{0})$ & $-\boldsymbol{\phi}^{\prime}(\mathbf{0})$ & $\boldsymbol{C}_{f x} \mathbf{( 0 )}$ \\
\hline 0.1 & 0.1 & 6.5 & 5.0 & 0.1 & 1.0 & 1.0 & 0.1 & 0.9 & 0.1 & 0.5 & $45^{\circ}$ & 0.0936 & 1.6159 & 0.5417 \\
$\mathbf{0 . 5}$ & 0.1 & 6.5 & 5.0 & 0.1 & 1.0 & 1.0 & 0.1 & 0.9 & 0.1 & 0.5 & $45^{\circ}$ & 0.0447 & 1.6541 & 0.5449 \\
0.1 & $\mathbf{0 . 1 3}$ & 6.5 & 5.0 & 0.1 & 1.0 & 1.0 & 0.1 & 0.9 & 0.1 & 0.5 & $45^{\circ}$ & 0.0961 & 1.6038 & 0.5406 \\
0.1 & 0.1 & $\mathbf{1 0 . 0}$ & 5.0 & 0.1 & 1.0 & 1.0 & 0.1 & 0.9 & 0.1 & 0.5 & $45^{\circ}$ & 0.0563 & 1.7133 & 0.6235 \\
0.1 & 0.1 & 6.5 & $\mathbf{1 0 . 0}$ & 0.1 & 1.0 & 1.0 & 0.1 & 0.9 & 0.1 & 0.5 & $45^{\circ}$ & 0.0919 & 2.3622 & 0.5785 \\
0.1 & 0.1 & 6.5 & 5.0 & $\mathbf{0 . 3}$ & 1.0 & 1.0 & 0.1 & 0.9 & 0.1 & 0.5 & $45^{\circ}$ & 0.0957 & 1.5958 & 0.6332 \\
0.1 & 0.1 & 6.5 & 5.0 & 0.1 & $\mathbf{5 . 0}$ & 1.0 & 0.1 & 0.9 & 0.1 & 0.5 & $45^{\circ}$ & 0.0527 & 1.6374 & 0.5421 \\
0.1 & 0.1 & 6.5 & 5.0 & 0.1 & 1.0 & $\mathbf{5 . 0}$ & 0.1 & 0.9 & 0.1 & 0.5 & $45^{\circ}$ & 0.0916 & 1.5833 & 0.6563 \\
0.1 & 0.1 & 6.5 & 5.0 & 0.1 & 1.0 & 1.0 & $\mathbf{1 . 0}$ & 0.9 & 0.1 & 0.5 & $45^{\circ}$ & 0.0952 & 1.6184 & 0.5250 \\
0.1 & 0.1 & 6.5 & 5.0 & 0.1 & 1.0 & 1.0 & 0.1 & $\mathbf{2 . 0}$ & 0.1 & 0.5 & $45^{\circ}$ & 0.0949 & 1.6376 & 0.3809 \\
0.1 & 0.1 & 6.5 & 5.0 & 0.1 & 1.0 & 1.0 & 0.1 & 0.9 & $\mathbf{0 . 2}$ & 0.5 & $45^{\circ}$ & 0.1779 & 1.5828 & 0.5363 \\
0.1 & 0.1 & 6.5 & 5.0 & 0.1 & 1.0 & 1.0 & 0.1 & 0.9 & 0.1 & $\mathbf{1 . 5}$ & $45^{\circ}$ & 0.1253 & 1.5763 & 0.6968 \\
0.1 & 0.1 & 6.5 & 5.0 & 0.1 & 1.0 & 1.0 & 0.1 & 0.9 & 0.1 & 0.5 & $\mathbf{6 0}$ & 0.0968 & 1.6098 & 0.5818 \\
\hline
\end{tabular}

Figure 2 demonstrates the velocity profile against the magnetic effect. It is observed that the magnetic parameter produces Lorentz force, due to which the velocity of the fluid retards and the velocity profile drops for higher values of the magnetic parameter. Moreover, Figure 3 shows that the temperature contour is enhanced by upgrading the magnetic parameter, and the reason behind this is that the Lorentz force boosts the temperature. Consequently, the thickness of the boundary layer upturns with the increasing of the magnetic parameter. Besides, a different effect of magnetic field on concentration is noticed in Figure 4.

The influence of the nonlinear parameter on the velocity profile is shown in Figure 5. It is noted that the velocity field is not much pronounced in the case of a linear or nonlinear stretching sheet as compared to a uniformly moving surface. Similar behavior is shown in Figure 6 for the temperature profile. Moreover, an opposite effect is shown in Figure 7 for the concentration profile. Figure 8 represents the Casson effect suppressed the velocity of the fluid. It is meaningful because $\beta$ reduces the yield stress in the Casson fluid. Physically, an enhancement in the Casson parameter tends to reduce the yield stress, which implies that the plastic dynamic viscosity of the liquid is enhanced and the momentum boundary layer becomes thicker [46]. 


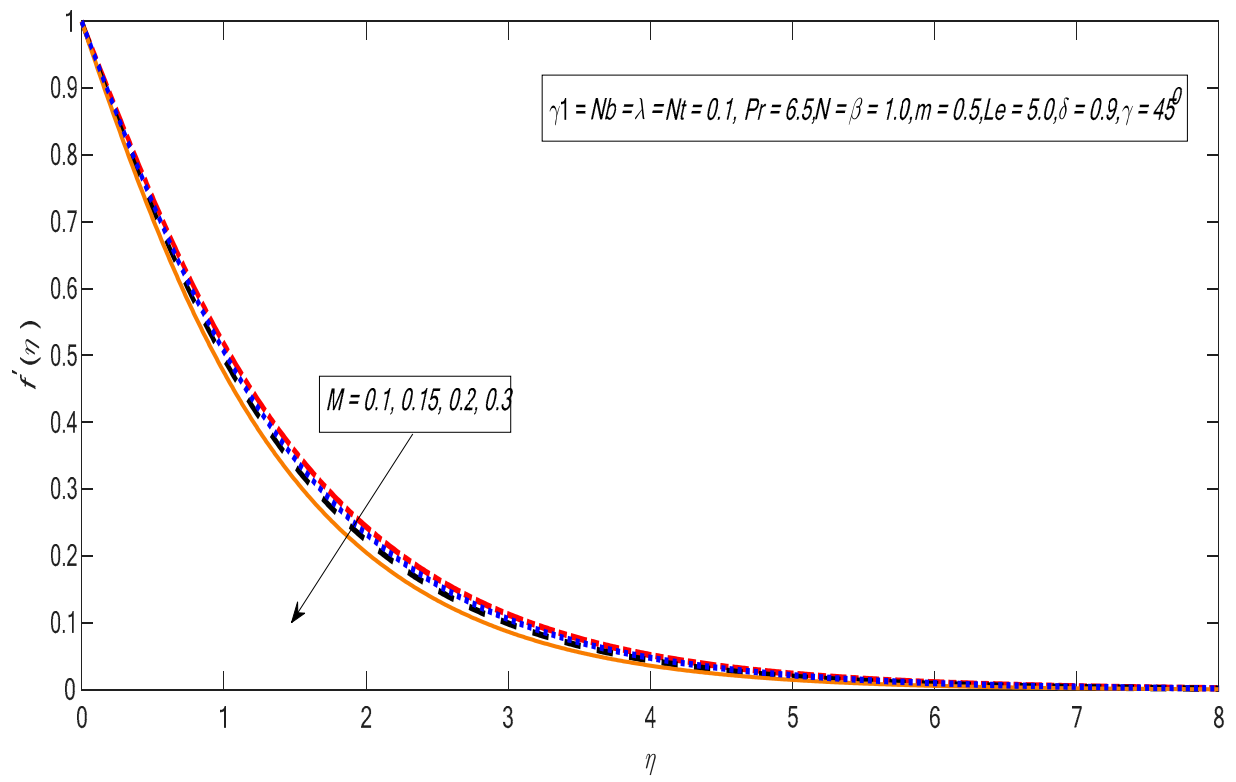

Figure 2. Variations in velocity profile for several values of $M$.

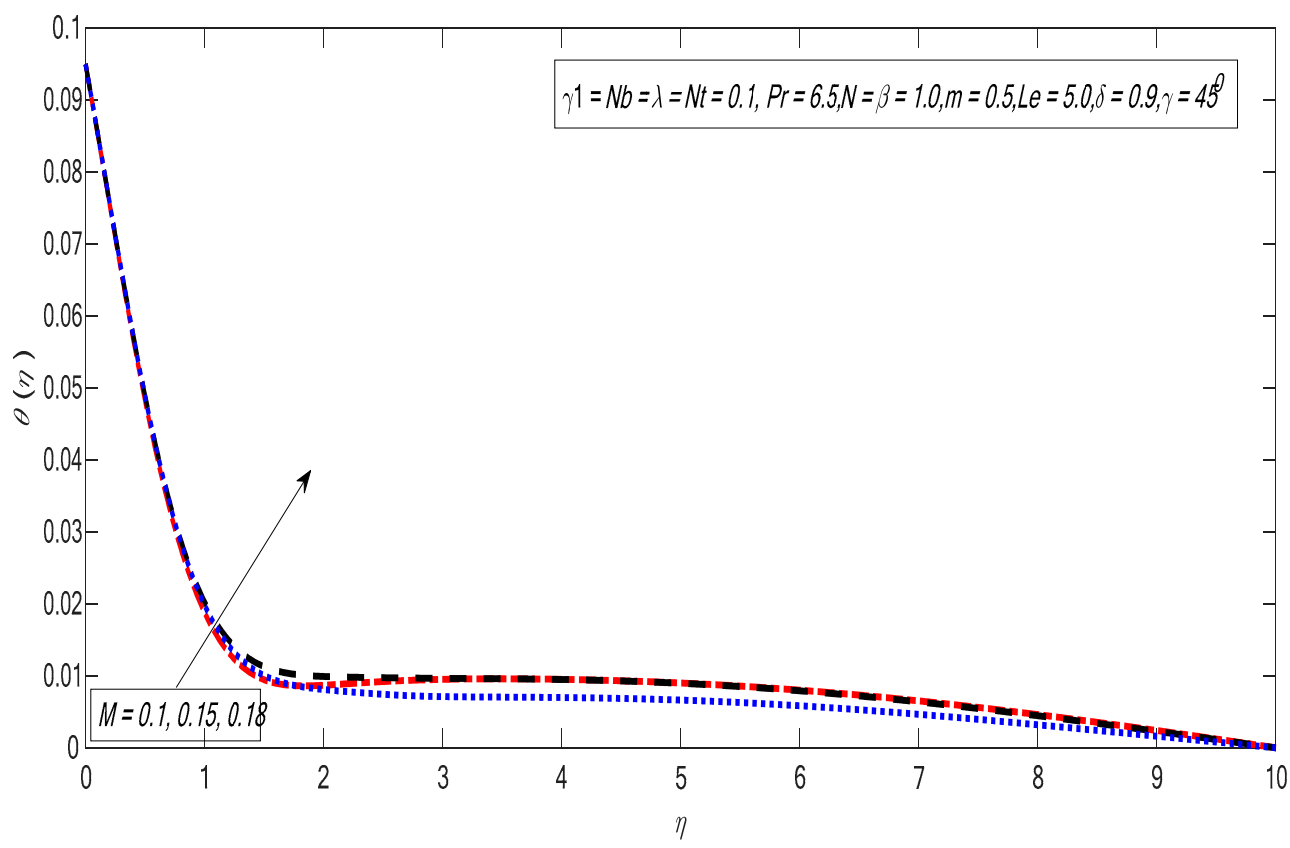

Figure 3. Variations in temperature profile for several values of $M$.

Figure 9 indicates that the buoyancy force parameter $\lambda$ has a directly proportional relation with the velocity profile. Physically, an increment in the buoyancy force causes a reduction of the viscous force, due to which the fluid particles move faster. In summary, the enhancement in buoyancy force tends to enhance the velocity profile. Figure 10 reveals the effect of solutal buoyancy impact on the velocity profile. The concentration difference, length and viscosity of the fluid affected the solutal buoyancy parameter. Therefore, as we enhance the solutal buoyancy parameter, the viscosity declines and the concentration increases, due to which the velocity of the fluid increases [47]. Figure 11 reflects the impact of inclination factor $\gamma$ on the velocity profile. It is observed in Figure 11 that the velocity contour runs down by improving the values of $\gamma$. Moreover, the conditions specify that the maximum gravitational force acts on the flow in the case of $\gamma=0$, because in this state the sheet will be vertical. On the other hand, for $\gamma=90^{\circ}$, the sheet will be horizontal, which causes a drop in velocity profile as the power of the bouncy forces drop. Figure 12 represents the impact of radiations 
on the temperature profile. It reveals that the temperature profile increases with large values of thermal radiation parameter; the reason behind this is that the heat exchange is enhanced and the boundary layer thickness declines [48]. Figure 13 indicates that the temperature profile is enhanced near the boundary layer by improving the values of the Biot number. A similar behavior in the case of concentration outline against higher values of the Biot number is seen in Figure 14.

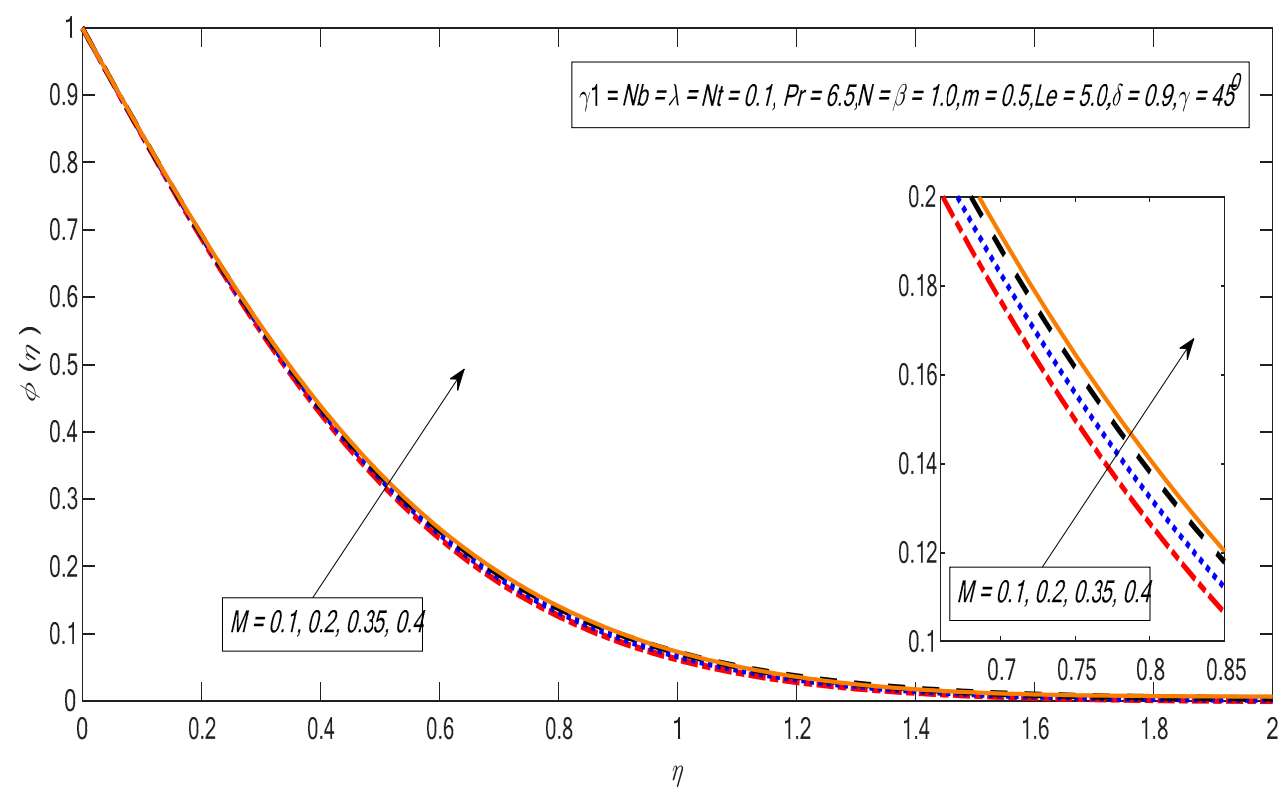

Figure 4. Variations in concentration profile for several values of $M$.

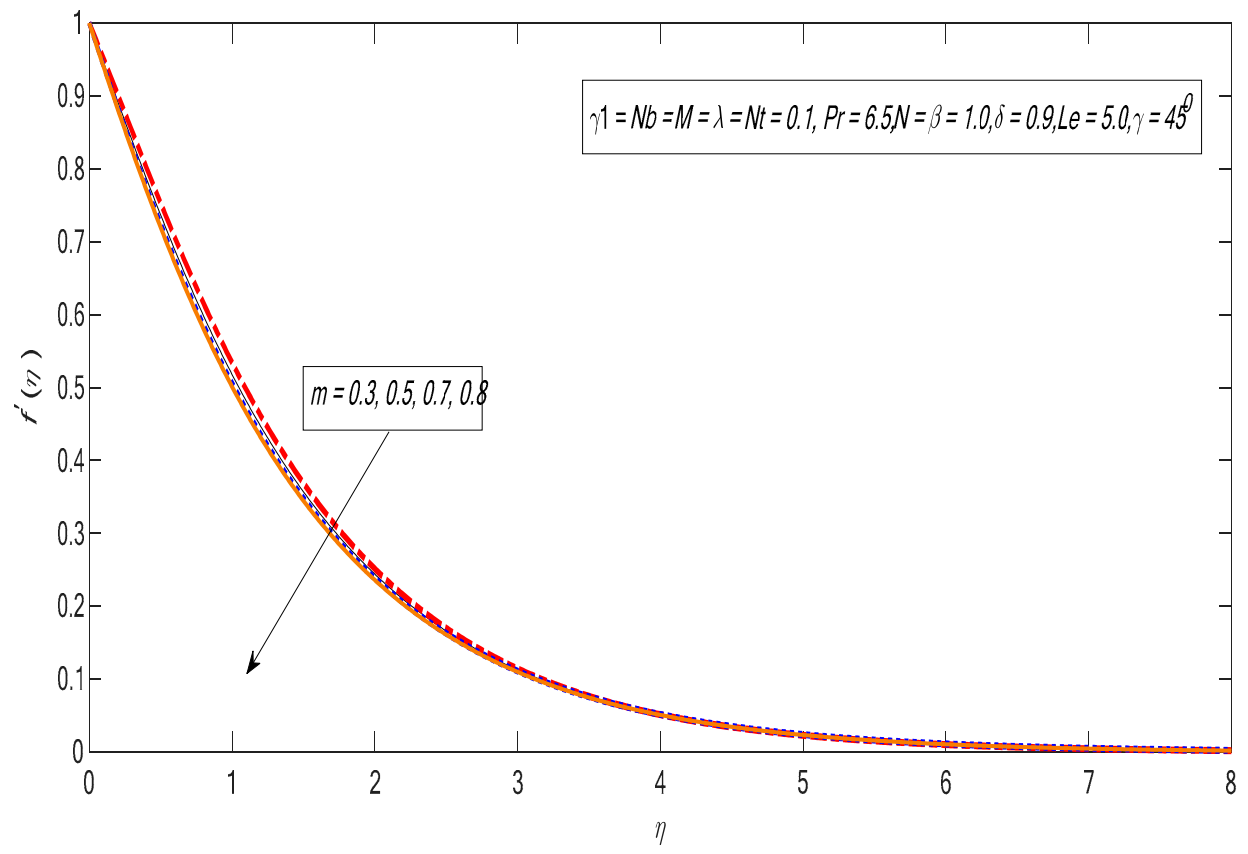

Figure 5. Variations in velocity profile for several values of $m$. 


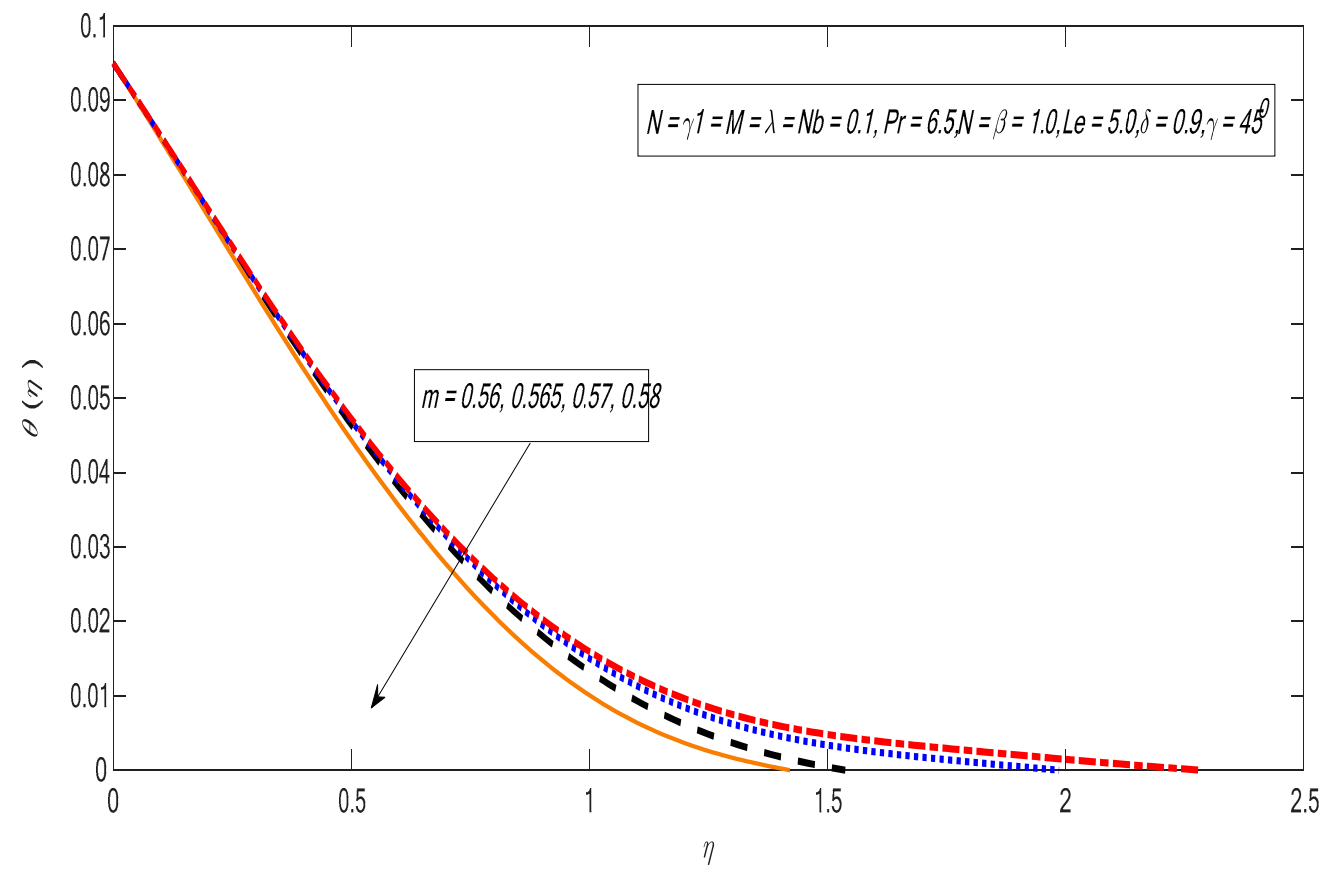

Figure 6. Variations in temperature profile for several values of $m$.

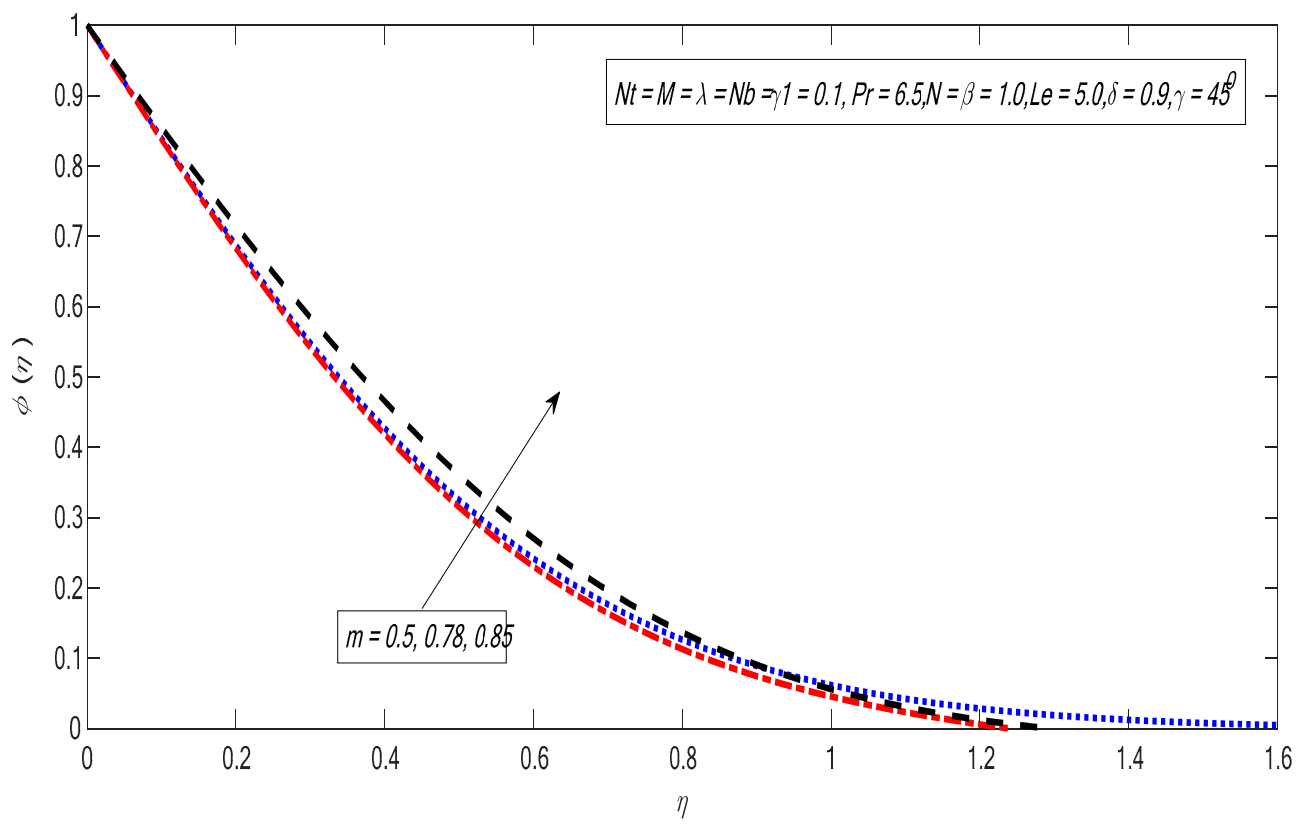

Figure 7. Variations in concentration profile for several values of $m$. 


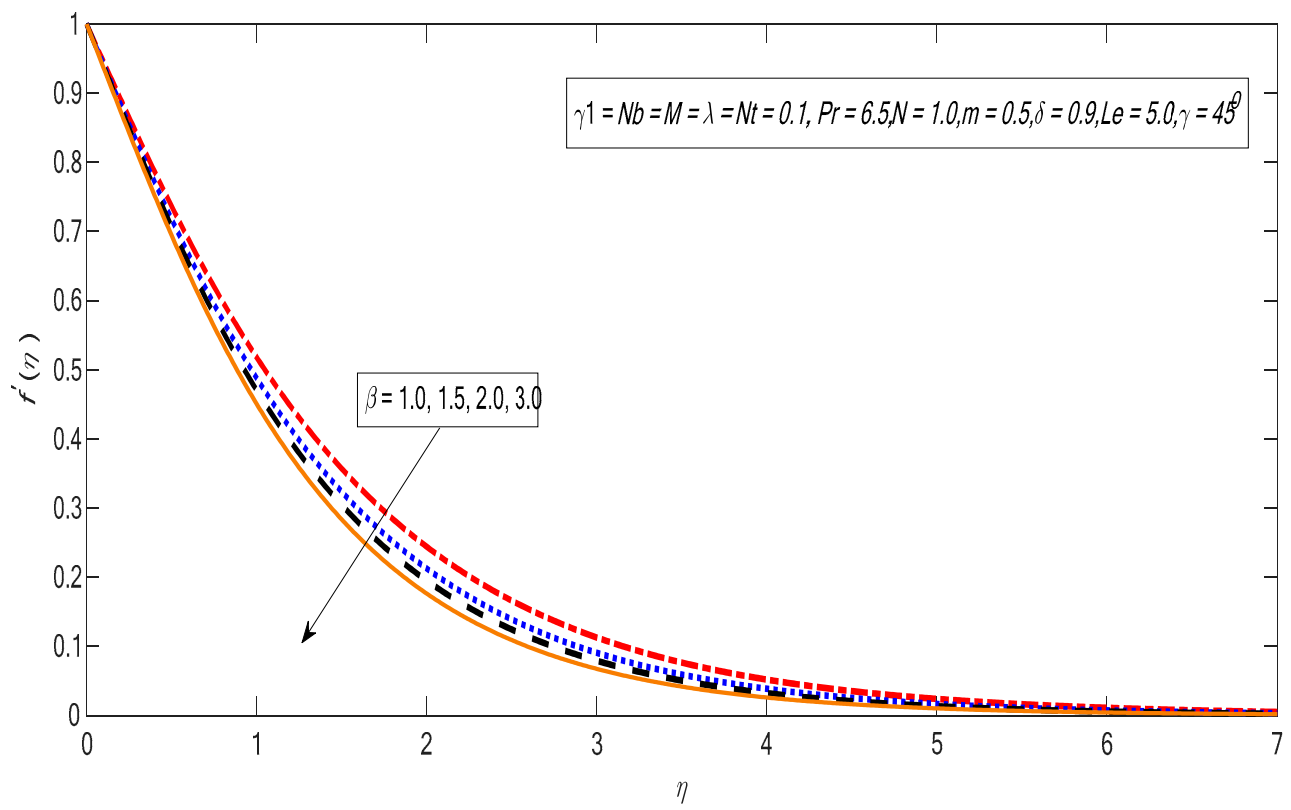

Figure 8. Variations in velocity profile for several values of $\beta$.

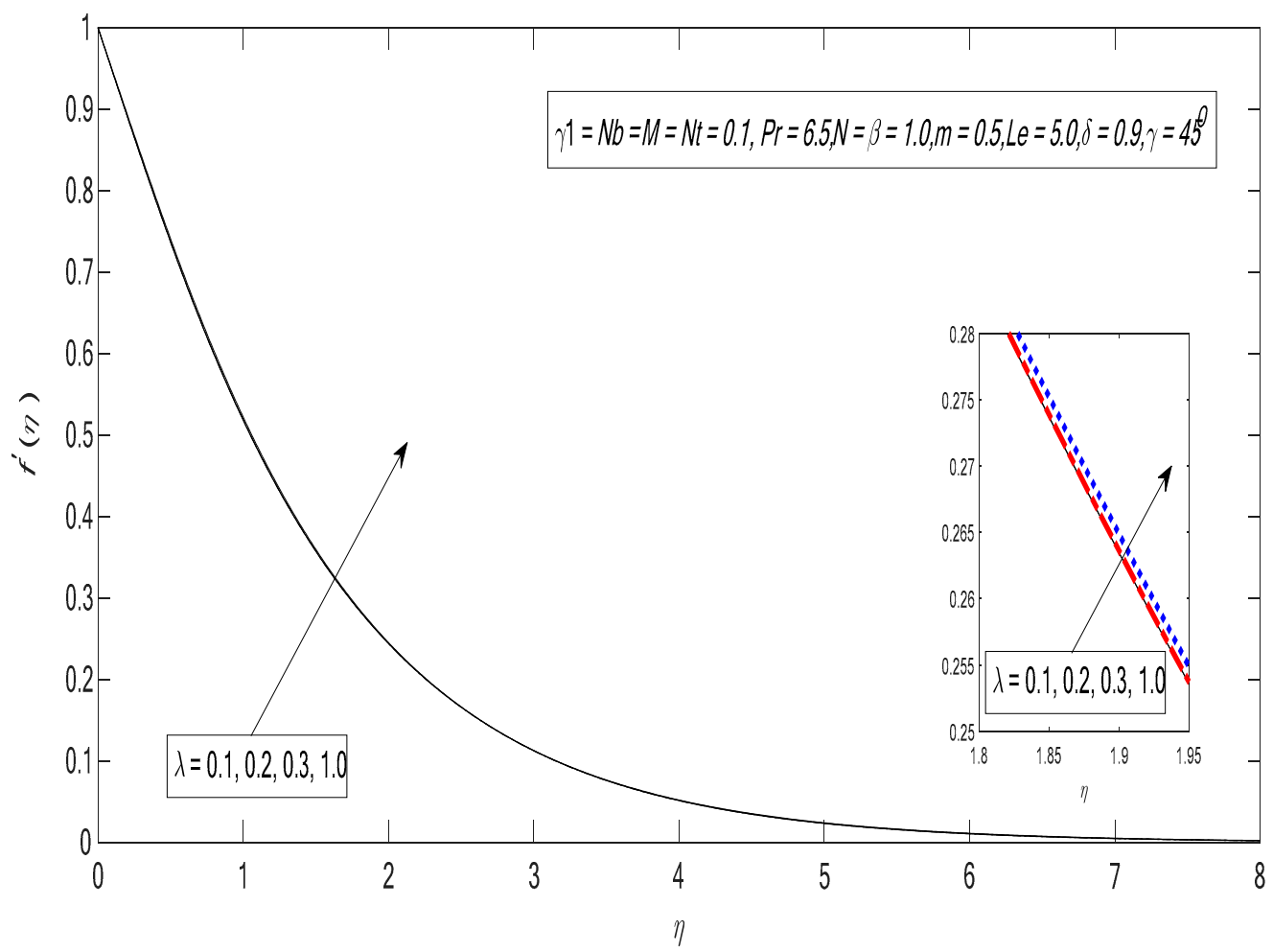

Figure 9. Variations in velocity profile for several values of $\lambda$. 


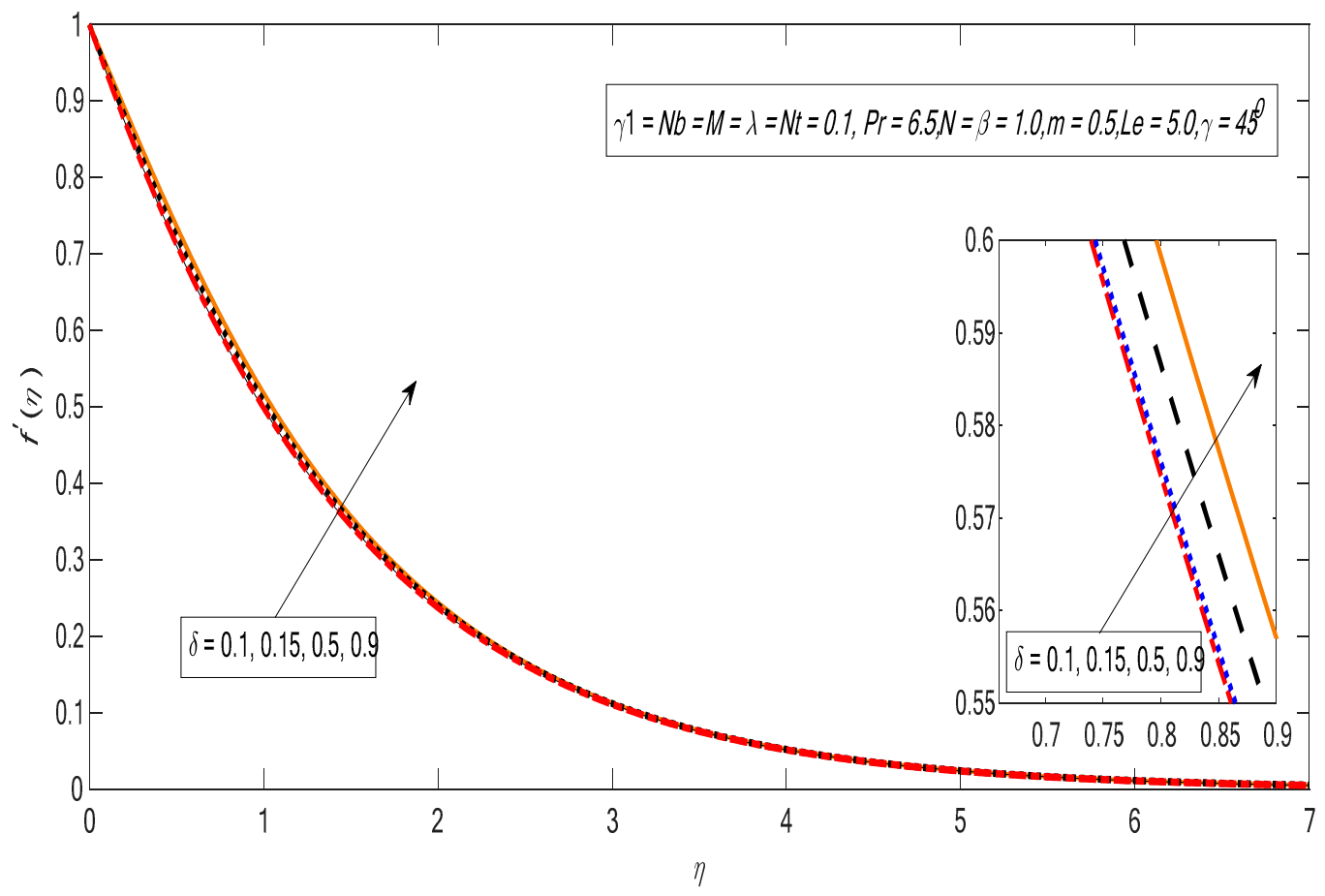

Figure 10. Variations in velocity profile for several values of $\delta$.

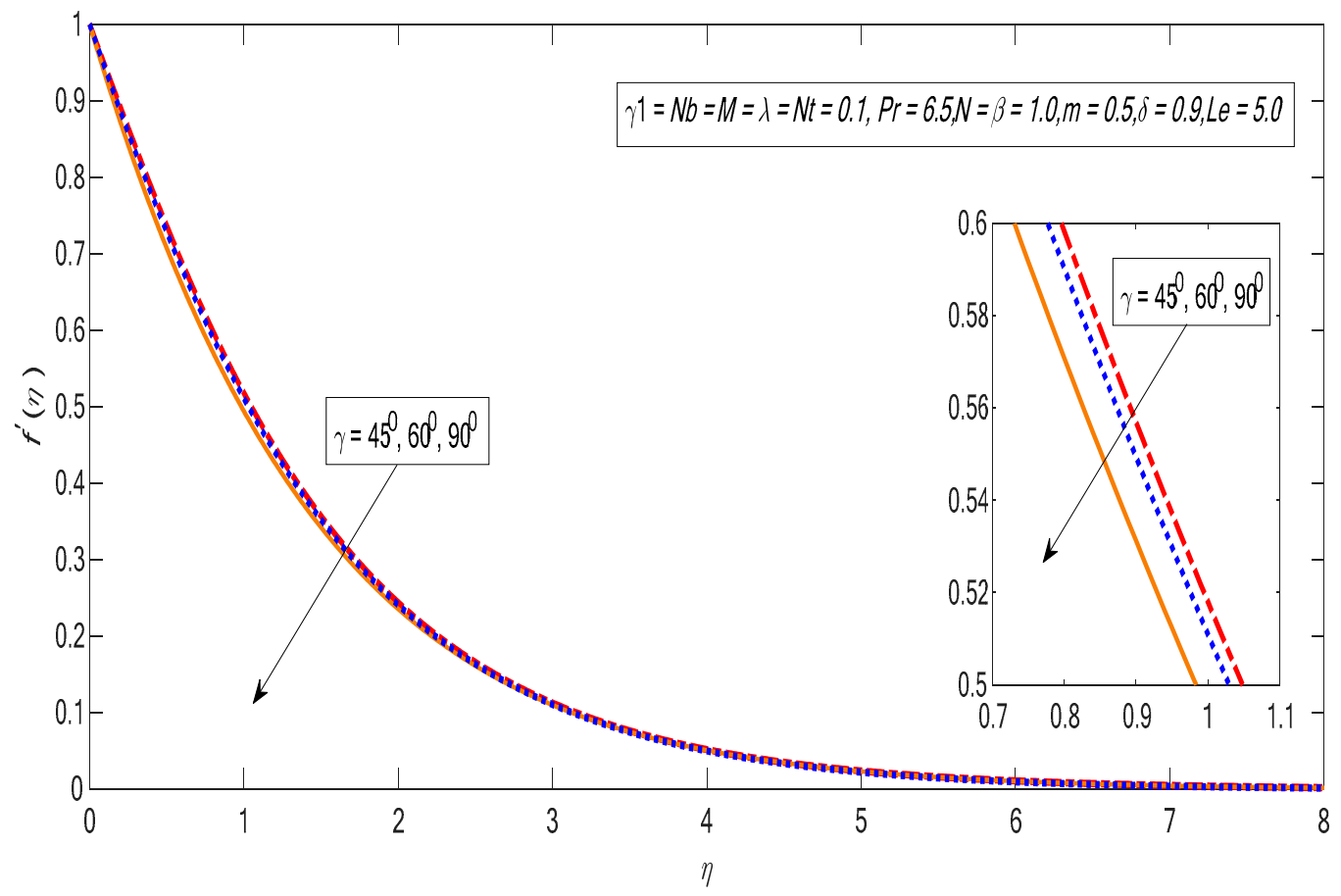

Figure 11. Variations in velocity profile for several values of $\gamma$. 


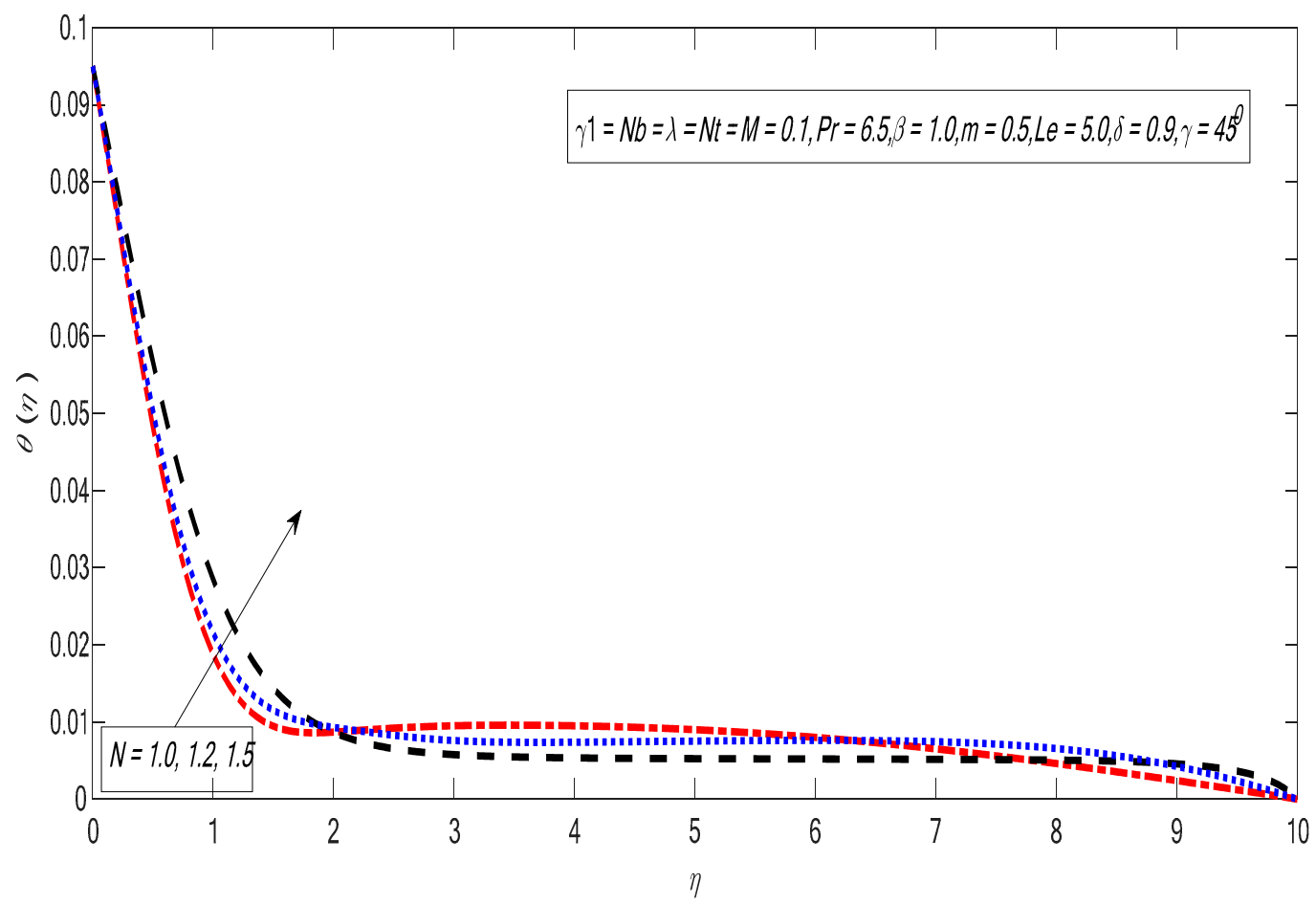

Figure 12. Variations in temperature profile for several values of $N$.

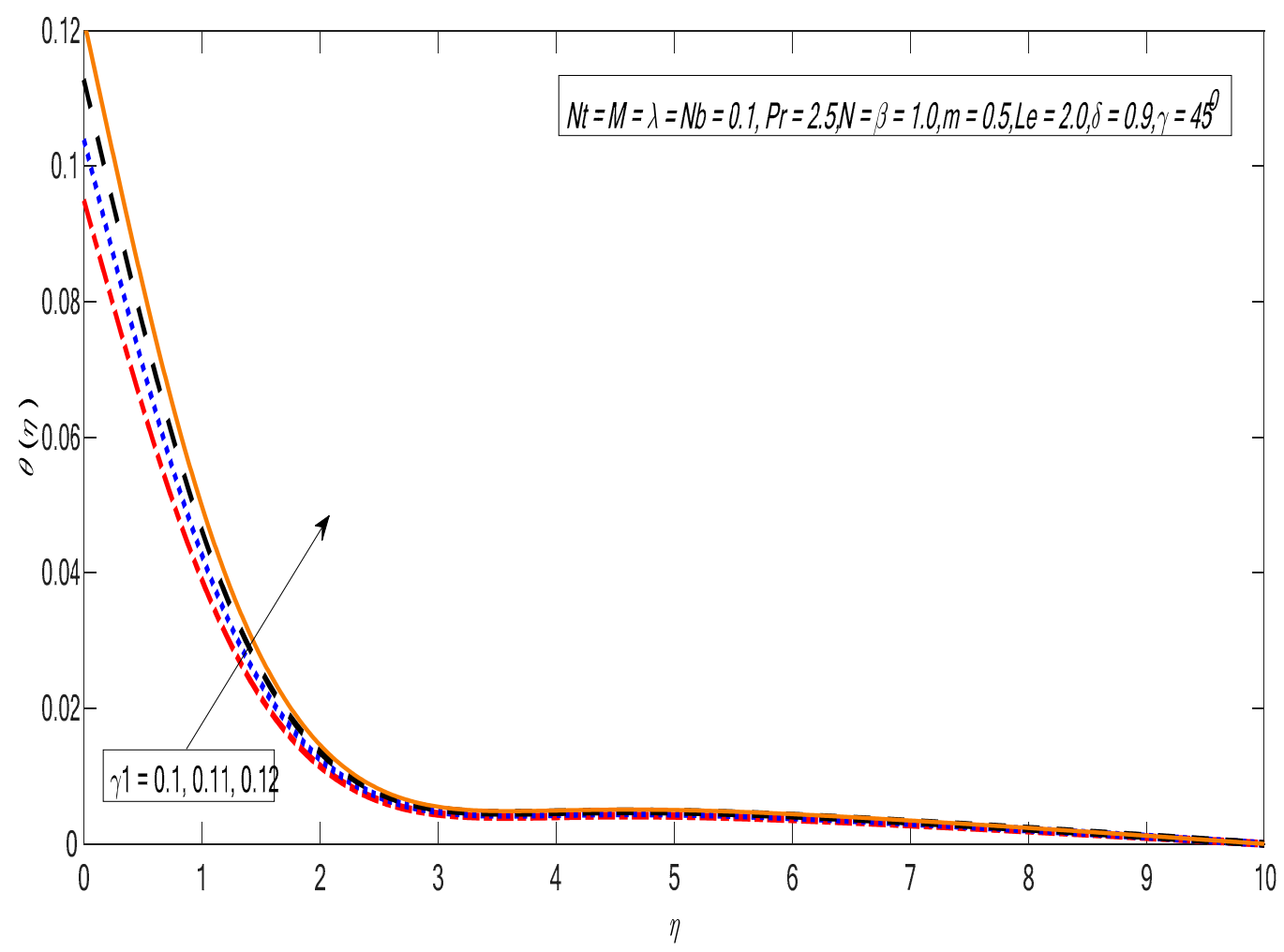

Figure 13. Variations in temperature profile for several values of $\gamma_{1}$. 


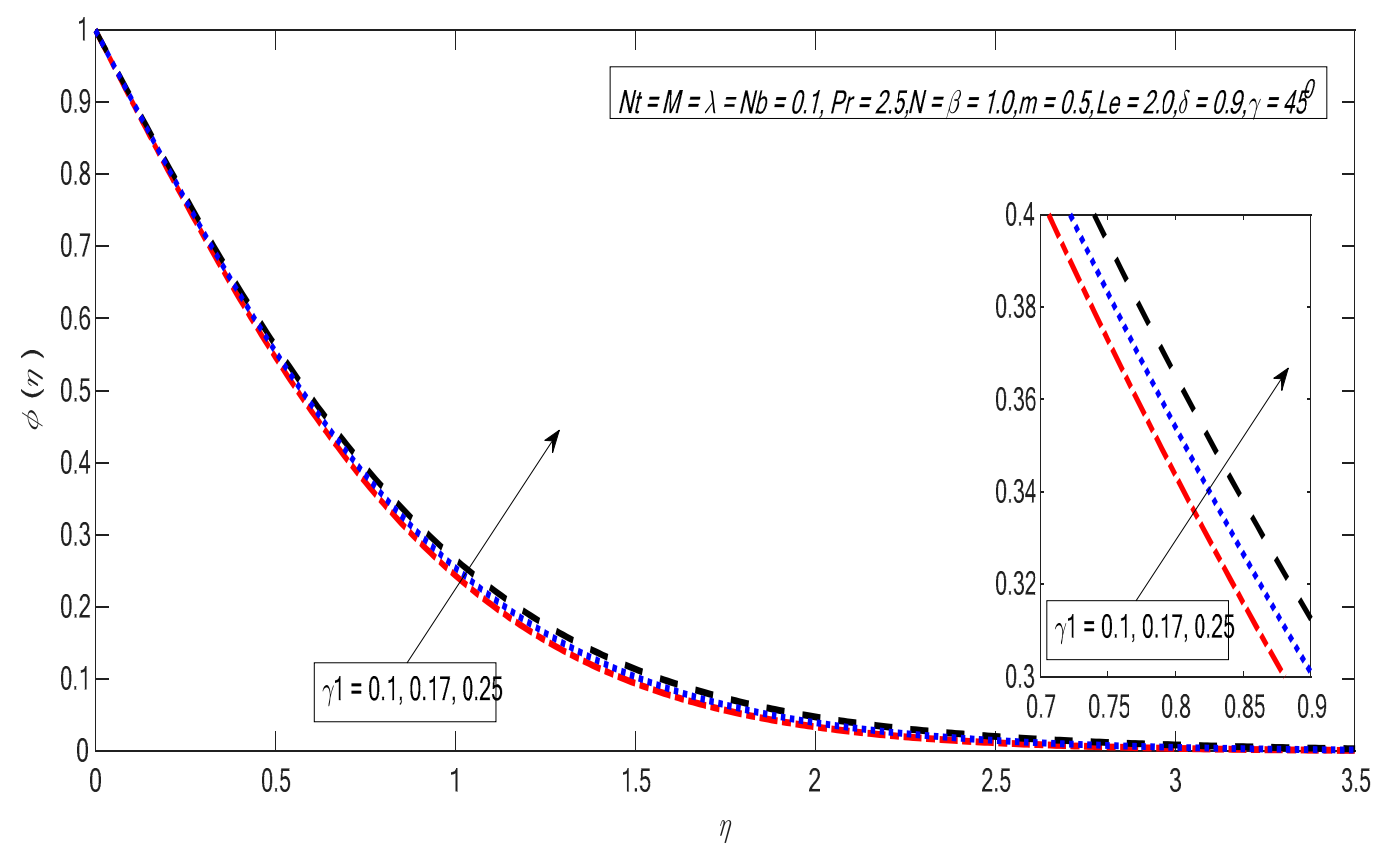

Figure 14. Variations in concentration profile for several values of $\gamma_{1}$.

Figure 15 represents that the temperature profile drops by improving the parameter $\mathrm{Pr}$. This is because the bigger values of $\operatorname{Pr}$ cause improvement in viscosity and decline in the thermal boundary layer thickness. Figure 16 shows the result of Lewis number Le on the concentration profile. The boundary layer viscosity reduces by enhancing the values of Lewis number $L e$.

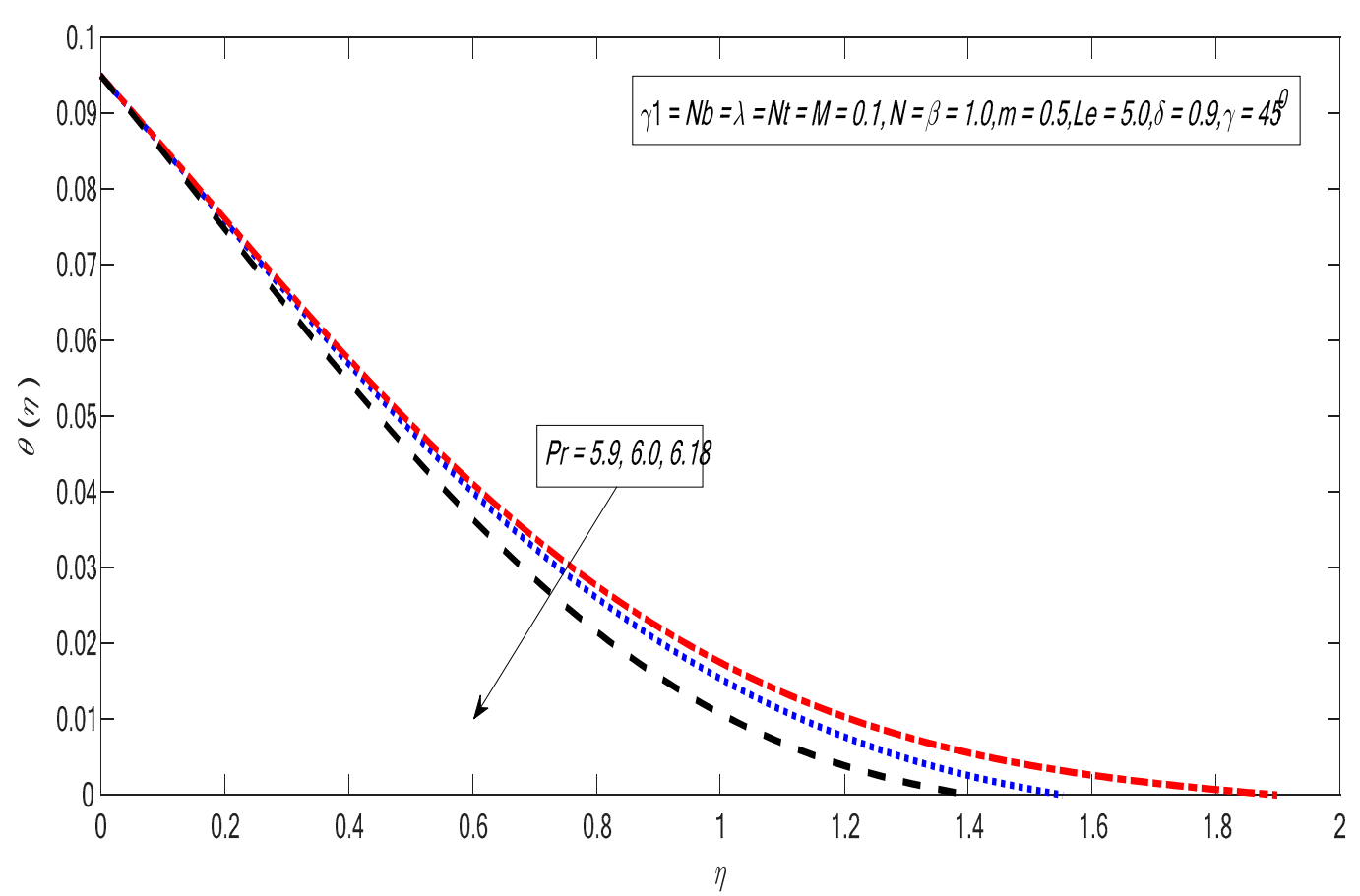

Figure 15. Variations in temperature profile for several values of $\mathrm{Pr}$. 


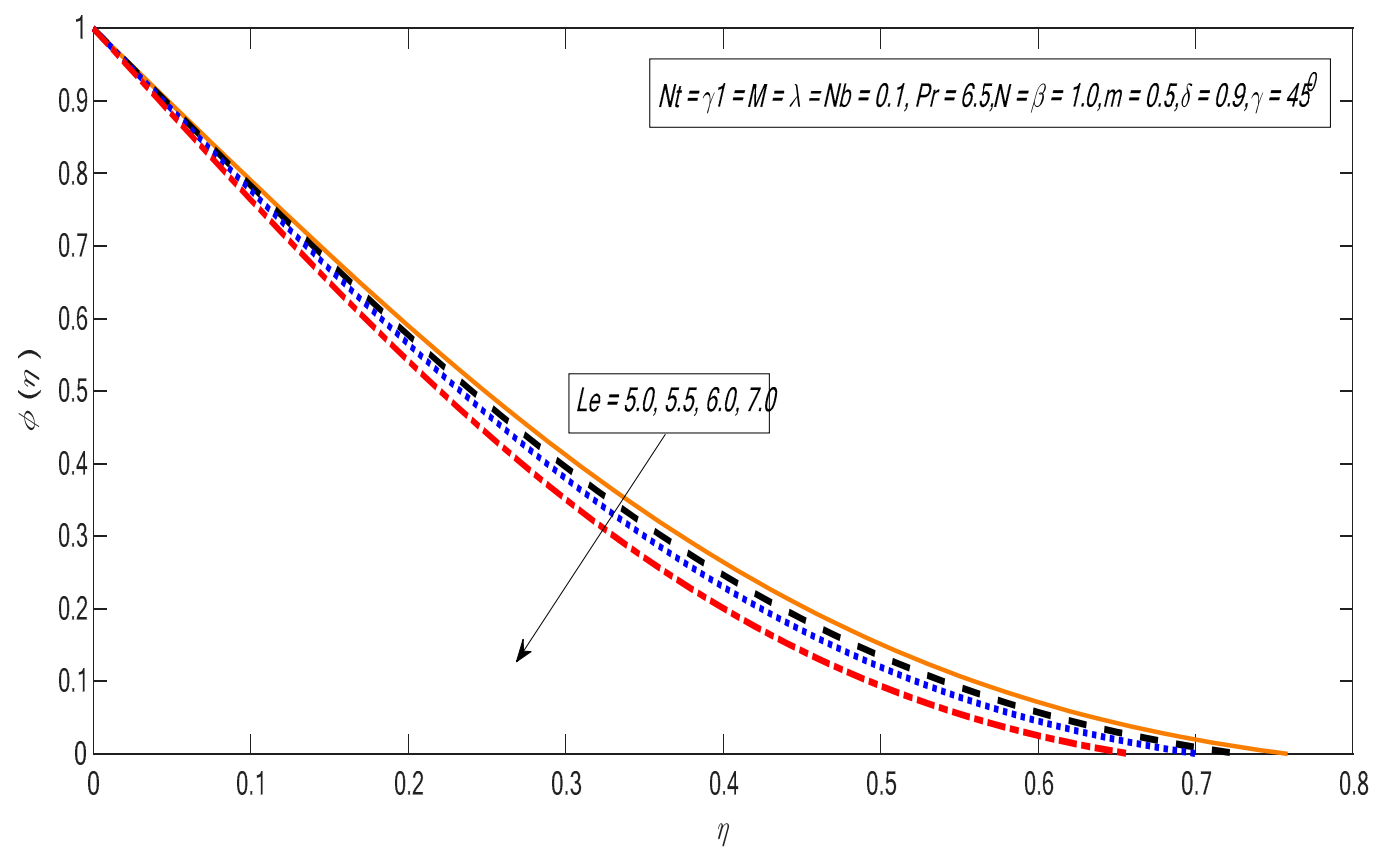

Figure 16. Variations in concentration profile for several values of $L e$.

Figures 17 and 18 show the effect of Brownian motion on the temperature and concentration profiles, respectively. The temperature profile upturns with improving $\mathrm{Nb}$; on the other hand, concentration distribution has the opposite impact. Physically, the boundary layer heats up due to the development in Brownian motion, which accelerates the nanoparticles from the extending sheet to the stationary fluid. Therefore, the concentration of nanoparticles reduces. Figures 19 and 20 reveal the impact of $N t$ on temperature and concentration profile for altered values. It is observed that both temperature and concentration contours are directly proportional to the $\mathrm{N} t$.

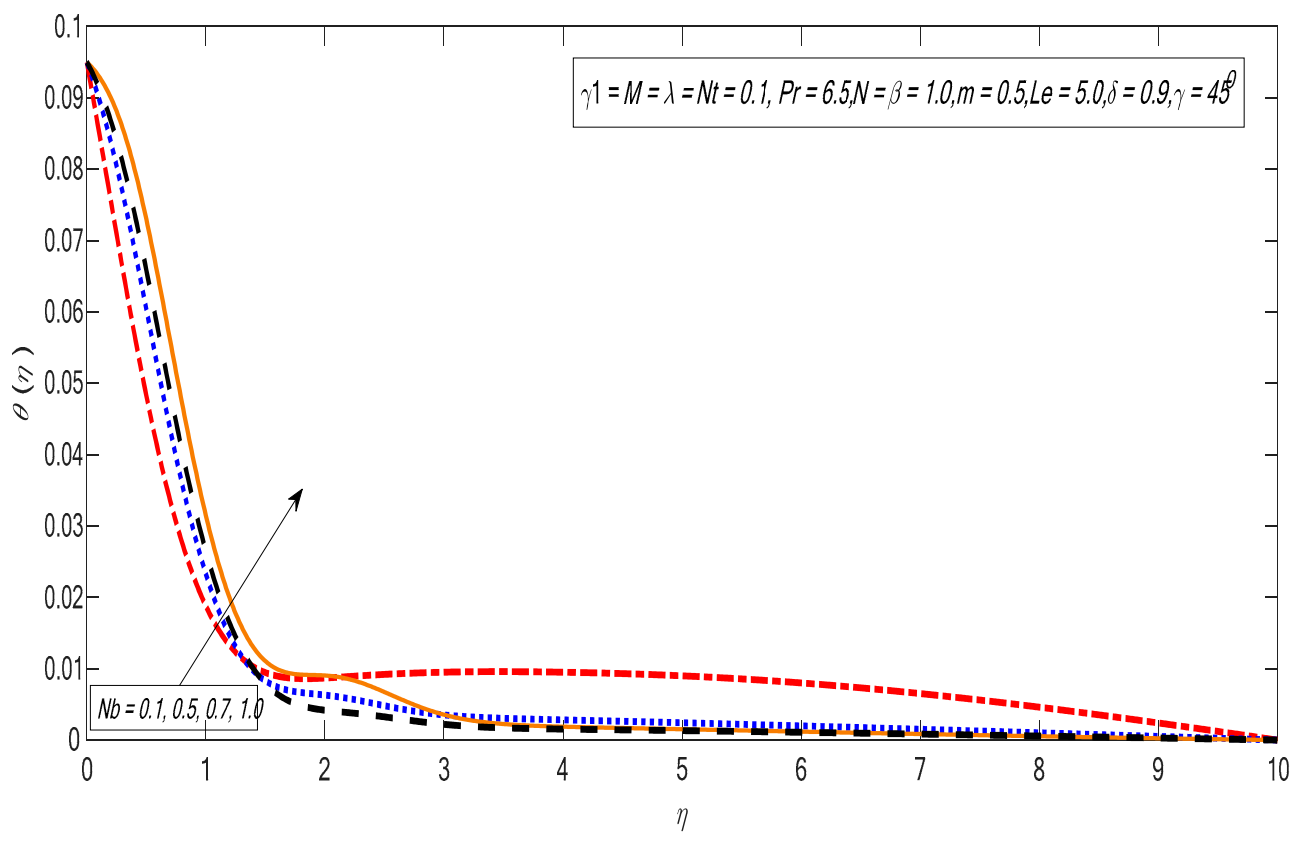

Figure 17. Variations in temperature profile for several values of $\mathrm{Nb}$. 


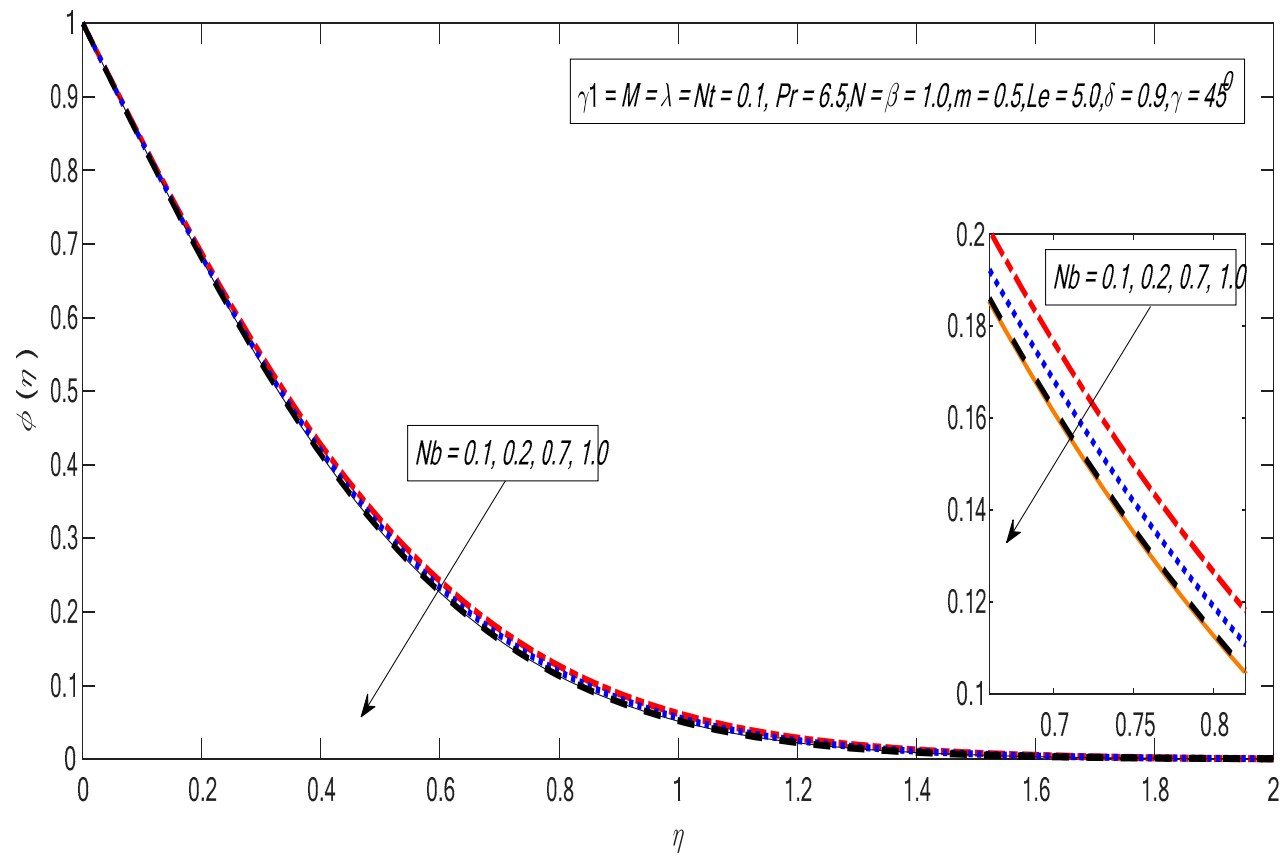

Figure 18. Variations in concentration profile for several values of $\mathrm{Nb}$.

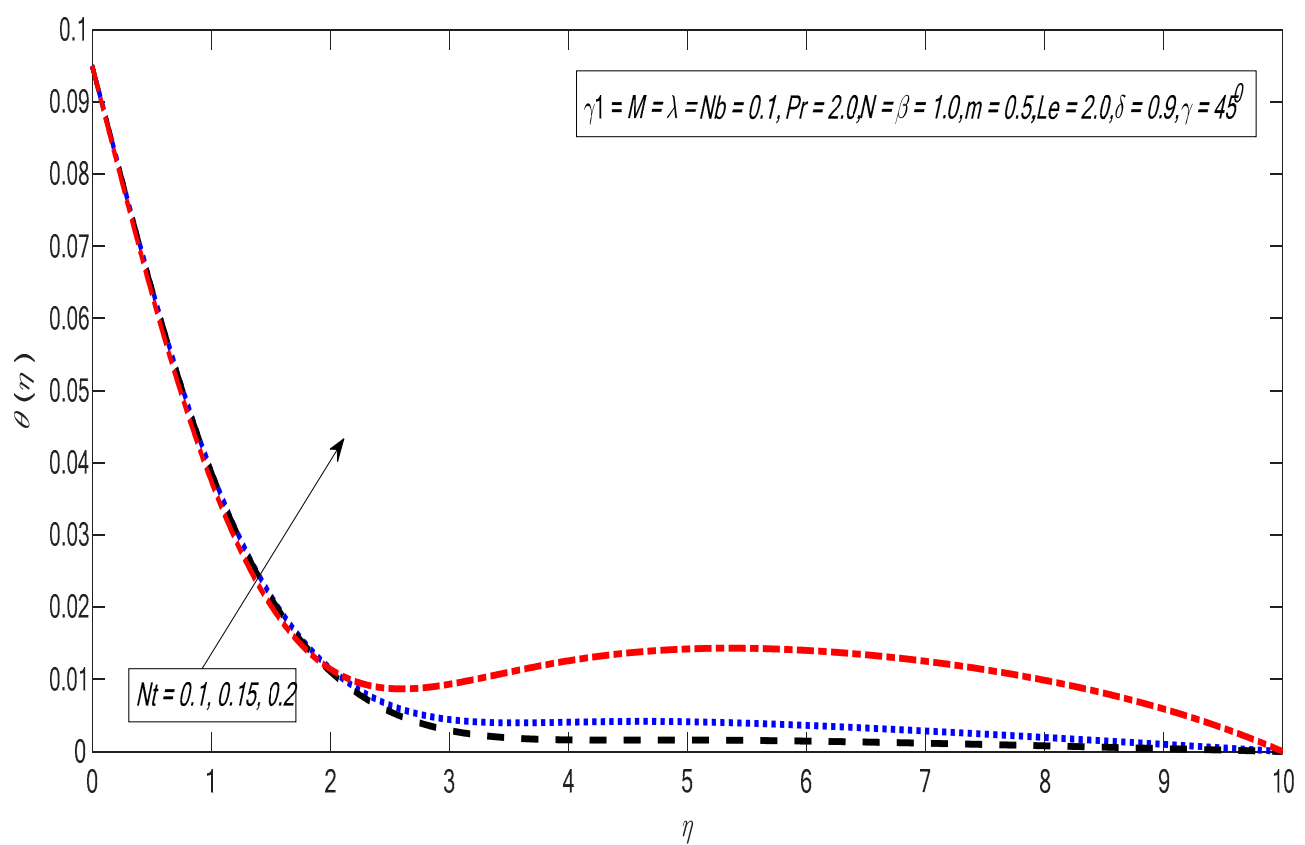

Figure 19. Variations in temperature profile for several values of $N t$. 


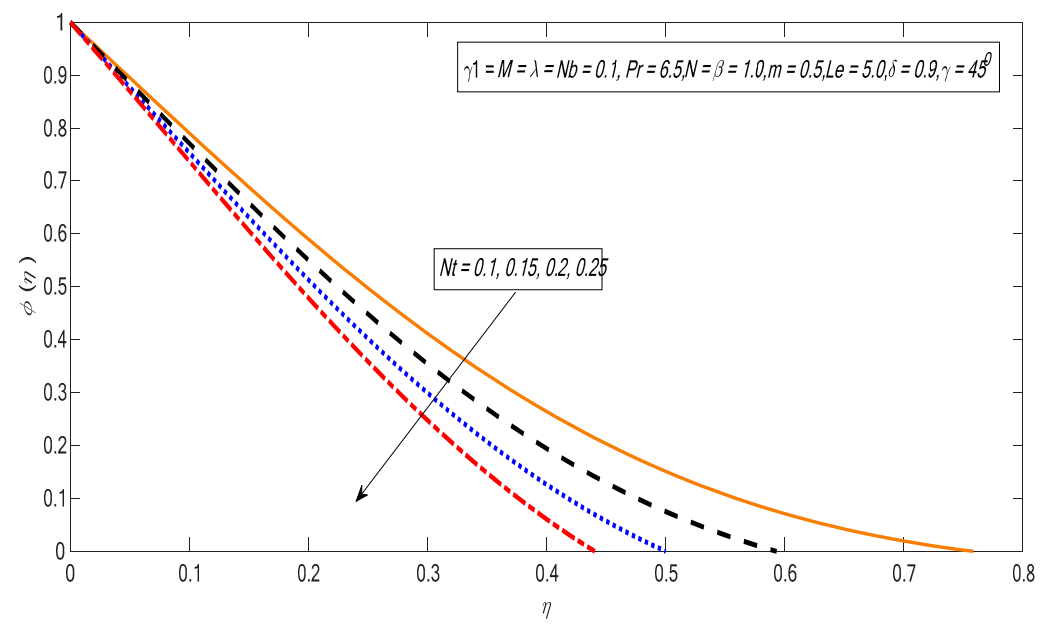

Figure 20. Variations in concentration profile for several values of $\mathrm{Nt}$.

\section{Conclusions}

In the article under study, we investigate the heat and mass transfer of Casson nanofluid flow over an inclined sheet, with convective boundaries and thermal radiation effects taken in account. The numerical results are elucidated with the Keller-box method. We found an excellent agreement between the current outcomes and already published results. The core findings of the problem under concern are the following:

$>$ The temperature profile increases near the boundary layer by improving the Biot number.

$>$ The velocity and temperature profiles drop by improving the nonlinear power index.

$>$ The heat exchange improved upon improving the radiation parameter.

$>$ The velocity distribution retards by increasing the Casson parameter.

$>$ The Nuselt number decreases by increasing the Casson parameter.

$>$ The skin friction declines by improving the Biot number.

$>$ The velocity profile shows an inverse relation with the inclination factor.

Author Contributions: M.I.A. and K.R. formulated the problem. M.M.; S.O.A. and P.T. elucidated the numerical results. K.S.N. and I.K. plotted and discussed the results.

Funding: This research received no external funding.

Acknowledgments: The authors would like to thank Deanship of Scientific Research, Majmaah University for supporting this work.

Conflicts of Interest: The authors declare that they have no conflict of interest.

\section{References}

1. Anwar, M.I.; Tanveer, N.; Salleh, M.Z.; Shafie, S. Diffusive effects on hydrodynamic Casson nanofluid boundary layer flow over a stretching surface. In Journal of Physics: Conference Series; IOP Publishing: Bristol, UK, 2017; Volume 890, p. 012047.

2. Afify, A.A. The influence of slip boundary condition on Casson nanofluid flow over a stretching sheet in the presence of viscous dissipation and chemical reaction. Math. Probl. Eng. 2017, 2017, 3804751. [CrossRef]

3. Souayeh, B.; Reddy, M.G.; Sreenivasulu, P.; Poornima, T.; Rahimi-Gorji, M.; Alarifi, I.M. Comparative analysis on non-linear radiative heat transfer on MHD Casson nanofluid past a thin needle. J. Mol. Liq. 2019, 284, 163-174. [CrossRef]

4. Rashidi, S.; Esfahani, J.; Ellahi, R. Convective heat transfer and particle motion in an obstructed duct with two side by side obstacles by means of DPM model. Appl. Sci. 2017, 7, 431. [CrossRef]

5. Bhatti, M.M.; Zeeshan, A.; Ellahi, R. Electromagnetohydrodynamic (EMHD) peristaltic flow of solid particles in a third-grade fluid with heat transfer. Mech. Ind. 2017, 18, 314. [CrossRef] 
6. Ellahi, R.; Zeeshan, A.; Hussain, F.; Abbas, T. Study of shiny film coating on multi-fluid flows of a rotating disk suspended with nano-sized silver and gold particles: A comparative analysis. Coatings 2018, 8, 422. [CrossRef]

7. Anwar, M.I.; Shafie, S.; Hayat, T.; Shehzad, S.A.; Salleh, M.Z. Numerical study for MHD stagnation-point flow of a micropolar nanofluid towards a stretching sheet. J. Braz. Soc. Mech. Sci. Eng. 2017, 39, 89-100. [CrossRef]

8. Mustafa, M.; Khan, J.A. Model for flow of Casson nanofluid past a non-linearly stretching sheet considering magnetic field effects. AIP Adv. 2015, 5, 077148. [CrossRef]

9. Anwar, M.I.; Shafie, S.; Khan, I.; Ali, A.; Salleh, M.Z. Dufour and Soret effects on free convection flow of Nanofluid past a power law stretching sheet. Int. J. Appl. Maths Stats 2013, 43.

10. Anwar, M.I.; Khan, I.; Sharidan, S.; Salleh, M.Z. Conjugate effects of heat and mass transfer of nanofluids over a nonlinear stretching sheet. Int. J. Phys. Sci. 2012, 7, 4081-4092. [CrossRef]

11. Qing, J.; Bhatti, M.; Abbas, M.; Rashidi, M.; Ali, M. Entropy generation on MHD Casson nanofluid flow over a porous stretching/shrinking surface. Entropy 2016, 18, 123. [CrossRef]

12. Abbas, T.; Bhatti, M.M.; Ayub, M. Aiding and opposing of mixed convection Casson nanofluid flow with chemical reactions through a porous Riga plate. Proc. Inst. Mech. Eng. Part E J. Process. Mech. Eng. 2018, 232, 519-527. [CrossRef]

13. Choi, S.U.S.; Singer, D.A.; Wang, H.P. Developments and applications of non-Newtonian flows. ASME FED 1995, 66, 99-105. [CrossRef]

14. Asma, K.; Khan, I.; Arshad, K.; Sharidan, S.; Tlili, I. Case study of MHD blood flow in a porous medium with CNTS and thermal analysis. Case Stud. Therm. Eng. 2018, 12, 374-380.

15. Suriyakumar, P.; Devi, S.A. Effects of Suction and Internal Heat Generation on Hydromagnetic Mixed Convective Nanofluid Flow over an Inclined Stretching Plate. Eur. J. Adv. Eng. Technol. 2015, 2, 51-58.

16. Khan, M.; Shahid, A.; Malik, M.Y.; Salahuddin, T. Thermal and concentration diffusion in Jeffery nanofluid flow over an inclined stretching sheet: A generalized Fourier's and Fick's perspective. J. Mol. Liq. 2018, 251, 7-14. [CrossRef]

17. Thumma, T.; Beg, O.A.; Kadir, A. Numerical study of heat source/sink effects on dissipative magnetic nanofluid flow from a non-linear inclined stretching/shrinking sheet. J. Mol. Liq. 2017, 232, 159-173. [CrossRef]

18. Prakash, J.; Tripathi, D.; Triwari, A.K.; Sait, S.M.; Ellahi, R. Peristaltic Pumping of Nanofluids through a Tapered Channel in a Porous Environment: Applications in Blood Flow. Symmetry 2019, 11, 868. [CrossRef]

19. Zeeshan, A.; Shehzad, N.; Abbas, T.; Ellahi, R. Effects of radiative electro-magnetohydrodynamics diminishing internal energy of pressure-driven flow of titanium dioxide-water nanofluid due to entropy generation. Entropy 2019, 21, 236. [CrossRef]

20. Shehzad, N.; Zeeshan, A.; Ellahi, R.; Rashidi, S. Modelling study on internal energy loss due to entropy generation for non-darcy poiseuille flow of silver-water nanofluid: An application of purification. Entropy 2018, 20, 851. [CrossRef]

21. Hussain, F.; Ellahi, R.; Zeeshan, A. Mathematical models of electro-magnetohydrodynamic multiphase flows synthesis with nano-sized hafnium particles. Appl. Sci. 2018, 8, 275. [CrossRef]

22. Ellahi, R.; Zeeshan, A.; Hussain, F.; Abbas, T. Thermally Charged MHD Bi-phase Flow Coatings with non-Newtonian Nanofluid and Hafnium Particles along Slippery Walls. Coatings 2019, 9, 300. [CrossRef]

23. Rashad, A. Unsteady nanofluid flow over an inclined stretching surface with convective boundary condition and anisotropic slip impact. Int. J. Heat Technol. 2017, 35, 82-90. [CrossRef]

24. Govindarajan, A. Radiative fluid flow of a nanofluid over an inclined plate with non-uniform surface temperature. In Journal of Physics: Conference Series; IOP Publishing: Bristol, UK, 2018; Volume 1000, p. 12173.

25. Hatami, M.; Jing, D.; Yousif, M.A. Three-dimensional analysis of condensation nanofluid film on an inclined rotating disk by efficient analytical methods. Arab J. Basic Appl. Sci. 2018, 25, 28-37. [CrossRef]

26. Cimpean, D.S.; Pop, I. Fully developed mixed convection flow of a nanofluid through an inclined channel filled with a porous medium. Int. J. Heat Mass Transf. 2012, 55, 907-914. [CrossRef]

27. Reddy, P.B.A. Magnetohydrodynamic flow of a Casson fluid over an exponentially inclined permeable stretching surface with thermal radiation and chemical reaction. Ain Shams Eng. J. 2016, 7, 593-602. [CrossRef] 
28. Hakeem, A.A.; Renuka, P.; Ganesh, N.V.; Kalaivanan, R.; Ganga, B. Influence of inclined Lorentz forces on boundary layer flow of Casson fluid over an impermeable stretching sheet with heat transfer. J. Magn. Magn. Mater. 2016, 401, 354-361. [CrossRef]

29. Rawi, N.A.; Ilias, M.R.; Lim, Y.J.; Isa, Z.M.; Shafie, S. Unsteady mixed convection flow of Casson fluid past an inclined stretching sheet in the presence of nanoparticles. In Journal of Physics: Conference Series; IOP Publishing: Bristol, UK, 2017; Volume 890, p. 012048.

30. Jain, S.; Parmar, A. Multiple slip effects on inclined MHD Casson fluid flow over a permeable stretching surface and a melting surface. Int. J. Heat Technol. 2018, 36, 585-594. [CrossRef]

31. Ali, M.; Alim, M.A.; Alam, M.S. Similarity solution of heat and mass transfer flow over an inclined stretching sheet with viscous dissipation and constant heat flux in presence of magnetic field. Procedia Eng. 2015, 105, 557-569. [CrossRef]

32. Ellahi, R.; Zeeshan, A.; Hussain, F.; Asadollahi, A. Peristaltic blood flow of couple stress fluid suspended with nanoparticles under the influence of chemical reaction and activation energy. Symmetry 2019, 11, 276. [CrossRef]

33. Bohra, S. Heat and mass transfer over a three-dimensional inclined non-linear stretching sheet with convective boundary conditions. Indian J. Pure Appl. Phys. (IJPAP) 2017, 55, 847-856.

34. Khan, M.; Sardar, H.; Gulzar, M.M.; Alshomrani, A.S. On multiple solutions of non-Newtonian Carreau fluid flow over an inclined shrinking sheet. Results Phys. 2018, 8, 926-932. [CrossRef]

35. Alam, M.S.; Islam, M.R.; Ali, M.; Alim, M.A.; Alam, M.M. Magnetohydrodynamic boundary layer flow of non-Newtonian fluid and combined heat and mass transfer about an inclined stretching sheet. Open J. Appl. Sci. 2015, 5, 279. [CrossRef]

36. Rafique, K.; Anwar, M.I.; Misiran, M. Numerical Study on Micropolar Nanofluid Flow over an Inclined Surface by Means of Keller-Box. Asian J. Probab. Stat. 2019, 1-21. [CrossRef]

37. Bognár, G.; Gombkötő, I.; Hriczó, K. Non-Newtonian fluid flow down an inclined plane. In Proceedings of the 9th ASME/WSEAS International Conference on Fluid Mechanics and Aerodynamics, Florence, Italy, August 2011; pp. 23-25.

38. Reddy, V.R.; REDDY, M.S.; Nagendra, N.; Rao, A.S.; Reddy, M.S. Radiation Effect on Boundary Layer Flow of a Non Newtonian Jeffrey Fluid Past an Inclined Vertical Plate. i-Manag. J. Math. 2017, 6, 34.

39. Rafique, K.; Anwar, M.I.; Misiran, M. Keller-box Study on Casson Nano Fluid Flow over a Slanted Permeable Surface with Chemical Reaction. Asian Res. J. Math. 2019, 14, 1-17. [CrossRef]

40. Ellahi, R.; Zeeshan, A.; Hussain, F.; Abbas, T. Two-Phase Couette Flow of Couple Stress Fluid with Temperature Dependent Viscosity Thermally Affected by Magnetized Moving Surface. Symmetry 2019, 11, 647. [CrossRef]

41. Benos, L.T.; Mahabaleshwar, U.S.; Sakanaka, P.H.; Sarris, I.E. Thermal analysis of the unsteady sheet stretching subject to slip and magnetohydrodynamic effects. Therm. Sci. Eng. Prog. 2019, 13, 100367. [CrossRef]

42. Mastroberardino, A.; Mahabaleshwar, U.S. Mixed convection in viscoelastic flow due to a stretching sheet in a porous medium. J. Porous Media 2013, 16, 483-500. [CrossRef]

43. Ghadikolaei, S.S.; Hosseinzadeh, K.; Ganji, D.D.; Jafari, B. Nonlinear thermal radiation effect on magneto Casson nanofluid flow with Joule heating effect over an inclined porous stretching sheet. Case Stud. Therm. Eng. 2018, 12, 176-187. [CrossRef]

44. Saidulu, N.; Gangaiah, T.; Lakshmi, A.V. Radiation Effect on Mhd Flow of a Tangent Hyperbolic Nanofluid over an Inclined Exponentially Stretching Sheet. Int. J. Fluid Mech. Res. 2019, 46. [CrossRef]

45. Khan, W.A.; Pop, I. Boundary-layer flow of a nanofluid past a stretching sheet. Int. J. Heat Mass Transf. 2010, 53, 2477-2483. [CrossRef]

46. Hussanan, A.; Salleh, M.Z.; Alkasasbeh, H.T.; Khan, I. MHD flow and heat transfer in a Casson fluid over a nonlinearly stretching sheet with Newtonian heating. Heat Transf. Res. 2018, 49. [CrossRef]

47. Ullah, A.; Shah, Z.; Kumam, P.; Ayaz, M.; Islam, S.; Jameel, M. Viscoelastic MHD Nanofluid Thin Film Flow over an Unsteady Vertical Stretching Sheet with Entropy Generation. Processes 2019, 7, 262. [CrossRef]

48. Oyelakin, I.S.; Mondal, S.; Sibanda, P. Unsteady Casson nanofluid flow over a stretching sheet with thermal radiation, convective and slip boundary conditions. Alex. Eng. J. 2016, 55, 1025-1035. [CrossRef]

(C) 2019 by the authors. Licensee MDPI, Basel, Switzerland. This article is an open access article distributed under the terms and conditions of the Creative Commons Attribution (CC BY) license (http://creativecommons.org/licenses/by/4.0/). 